\title{
RECOMMENDATIONS FOR IMPROVED WELDING PROCEDURES FOR THICK STEEL PLATES THROUGH THERMO-MECHANICALANALYSIS
}

\author{
Omar A. Ibrahim ${ }^{1}$, Dimitrios G. Lignos ${ }^{2}$ and Colin A. Rogers ${ }^{3}$ \\ ${ }^{1}$ Assistant Professor. Dept. of Structural Engineering, Alexandria University. \\ Lotfy El-Sied st. off Gamal Abd El-Naser - Alexandria, Alexandria Governorate 11432, Egypt \\ Tel: +20 35910052 \\ email: omar.ibrahim@mail.mcgill.ca \\ ${ }^{2}$ Corresponding author \\ Associate Professor. Dept. of Civil and Environmental Engineering, Ecole Polytechnique Fédérale \\ de Lausanne (EPFL) \\ EPFL ENAC IIC RESSLab, GC B3 485, Station 18, CH-1015 Lausanne, Switzerland \\ email: dimitrios.lignos@epfl.ch \\ Tel. +41216932427 \\ Fax. +41216932868 \\ ${ }^{3}$ Associate Professor. Dept. of Civil Engineering and Applied Mechanics McGill University \\ Macdonald Engineering Building 817 Sherbrooke Street West Montreal, QC, Canada, H3A 0C3 \\ email: colin.rogers@mcgill.ca
}




\begin{abstract}
Welding of steel plates is accompanied by residual stresses that increase as the constraint provided by the welded components becomes greater. Consequently, crack initiation has been reported after welding thick plates due to the high residual stresses developed by the welding procedure. This is further exacerbated by the higher likelihood of imperfections present in thick steel plates due to the rolling and cooling process. The research described herein aims to develop improved submerged arc welding (SAW) procedures to reduce the residual stresses for steel plates of thickness greater than $50 \mathrm{~mm}$. Acceptance criteria are developed for discontinuities present in the steel plates prior to welding, to limit the probability of crack initiation. A parametric study of SAW procedure parameters was conducted utilizing a validated finite element model. Two welding procedures were recommended for thick steel plates. Discontinuity acceptance limits were also recommended for each welding procedure using a fracture toughness database and an expression developed to calculate the probability of a crack to initiate.
\end{abstract}

Keywords: Thick steel plates - Welding procedure - Welding simulation - Discontinuities acceptance criteria 


\section{$1 \quad$ Introduction}

In recent years, more stringent requirements have been employed for the design of steel infrastructure due to seismic and blast loading as well as the design complexity. For this reason, steel plates with thickness $50 \mathrm{~mm}$ and higher are becoming common in the steel construction industry to form heavy built-up sections. Connecting such components through welding is an essential part of construction; for example, the welding of built-up members composed of thick steel plates and splice connections. Welding thick plates employs higher heat input than that required for commonly used $25 \mathrm{~mm}$ plates. Additionally, the plate thickness provides substantial constraint to the contraction of the heated steel resulting in high post-welding tensile residual stresses that can lead to crack initiation (Blodgett \& Miller, 1993; Fisher \& Pense, 1987). Miller (2010) proposed a set of recommendations to reduce shrinkage stresses and restraints in welded thick plates, in addition to ensuring that minimum levels of fracture toughness be met. Although these recommendations are informative and provide fabricators with the knowledge to weld thick steel plates, they are of a qualitative nature. Furthermore, welding specifications (AWS D1.1, 2010; CAN/CSA-W59, 2013) have no special requirements for the welding of thick steel plates. According to AWS D1.1 (2010) "Table 3.2"; the required prequalified minimum preheat and interpass temperatures for the welding of steel plates increase according to the plate thickness. However, AWS D1.1 (2010) also states in "Tables 4.2 and 4.3" that in order to qualify a welding procedure for unlimited thickness, it is permissible to use test plates of $25 \mathrm{~mm}$ in thickness. Consequently, steel fabricators are using welding procedures qualified for thick plates that were tested on common $25 \mathrm{~mm}$ plates. With the increasing demand to use thick plates welding procedures (AWS D1.1, 2010; CAN/CSA-W59, 2013) should be revisited with the aim to develop quantitative welding recommendations for various design applications. To the best of our 
knowledge, there has not been a study to provide quantitative recommendations for the welding of thick steel plates.

Very few studies have been carried out to address the effect of different parameters of the welding procedure on the resulting residual stresses. Pilipenko (2001) utilized finite element modeling of the welding procedure to study two different mitigation techniques to reduce the resulting residual stresses in thick-walled ship hull structures; mechanical straightening and thermal tensioning. Both techniques showed a $35-45 \%$ decrease in peak tensile residual stresses. However, new residual stresses were generated in previously stress free regions. The ASTM A131 (2014) Gr. 50 steel plates (i.e., nominal $f_{y}=345 \mathrm{MPa}$ ) used in Pilipenko's study were of maximum thickness of $45 \mathrm{~mm}$. Yang (2008) conducted experiments to study the effect of submerged arc welding current and speed on the mechanical and physical properties of ASTM A516 Gr.70 (2015) (i.e., nominal $f_{y}=$ 480MPa) and ASTM A709 Gr.50 (2015) (i.e., nominal $f_{y}=345 \mathrm{MPa}$ ) steel. The dimensions of the welded sample plates were $915 \times 122 \times 17 \mathrm{~mm}$ (36x4.8x0.66in.). Yang concluded that high travel speed and welding current result in severe undercuts, and the toughness of both steel materials increased with higher welding current and speed. In addition, the percent elongation at the heat affected zone increased with travel speed but decreased with welding current.

This paper contains a proposal for an improved submerged arc welding (SAW) procedure for thick plates using a partial penetration butt joint. This was achieved based on a rigorous parametric study that investigated the main parameters affecting the resulting post-welding residual stresses in thick steel plates. The parametric study was conducted based on detailed thermo-mechanical finite element (FE) analysis. The FE simulations utilize a modeling approach for welding procedures of welded thick plates that was recently proposed by the authors (Ibrahim et al., 2016). The parametric study is divided into two phases; the first phase involves parameters directly related to the heat 
input and cooling rate. These parameters are; the welding temperature, the welding speed, and the preheat and inter-pass temperatures. The second phase involves a set of general parameters; the steel material quality, the welded plate thickness, the number of passes, as well as the welding sequence. The assessment of each parameter is based on two criteria; first the stress profile during and after the welding procedure. Second, the minimum computed crack size according to the resulting residual stresses; based on fracture toughness tests for the steel material (Ibrahim et al., 2017). The results of the parametric study are utilized to provide quantitative recommendations for the welding of thick steel plates that are currently used in steel construction practice in North America.

\section{Main Features of the Employed Thermo-Mechanical Finite Element Model for Welding Simulation}

Establishing a detailed parametric study for SAW procedures through experiments is time consuming and costly. Therefore, such parametric study can be conducted through detailed FE analysis. A simulation of the welding procedure for thick steel plates is developed using an uncoupled thermo-mechanical finite element model proposed by Ibrahim et al. (2016). The simulation is divided into two models; a heat-transfer model that produces temperature distributions at all stages of the welding procedure. The temperature distributions are then exported to a stress analysis model that calculates the corresponding strains and stresses, which have resulted from the temperature changes. The results of the numerical model are validated with fullscale welding experiments, involving thick plates, described in detail in Ibrahim et al. (2016). The validation is achieved by comparing temperature distribution results from the model with measured temperatures from the welding experiment at the same time and location for each welding pass. Additionally the stress distribution results from the model are validated with 
experimental results achieved from previous research (Chen \& Chang, 1993). In brief, the main parameters of the welding simulation are the heat input, preheat and inter-pass temperatures, steel material properties, thickness of the welded plate, number of passes and welding sequence. The heat input is simulated through the welding temperature, welding pass size and the welding travel speed. Preheat and inter-pass temperatures are modeled by applying heat boundary conditions at the required area on the surface of the base metal until the required temperature is achieved.

In order to validate the employed thermo-mechanical finite element approach, a heavy built-up box column, that experienced cracks after welding, is used. The box column is composed of two 660x75mm (26x3in.) plates and two 324x75mm (123/4x3in.) plates of ASTM A572 Gr.50 (2013) steel $\left(f_{y}=345 \mathrm{MPa}, f_{u}=450 \mathrm{MPa}\right)$, where $f_{y}$ is the yield stress and $f_{u}$ is the ultimate stress of the steel material. The material properties of the numerical model are calibrated through tensile tests conducted for standard coupons obtained from different locations of the heavy built-up box column. Additional Charpy-V-Notch $(\mathrm{CVN})$ tests are conducted to estimate the base metal and heat affected zone (HAZ) fracture toughness (Ibrahim et al., 2016). The welding procedure is conducted on two corners of the built-up column simultaneously using an automated SAW process with average heat input of $2.4 \mathrm{KJ} / \mathrm{mm}$, average current of $700 \mathrm{~A}$ and average voltage of $30 \mathrm{~V}$. These parameters reflect standard welding practice in North America. Each corner is a partial joint penetration (PJP) weld, with groove depth of $37.5 \mathrm{~mm}$ and groove angle of $60^{\circ}$, consisting of 13 passes according to specifications suggested in AWS D1.1 (2010). Due to symmetry, only half the built-up box is modeled, as shown in Figure 1a. The electrodes used for this procedure are F7A4-EM12K according to AWS D1.1 A5.17 (AWS D1.1, 2010) with suitable granular flux type (OK FLUX 10.71). Two electrodes are used at each corner with diameter $2.4 \mathrm{~mm}$ and an $8 \mathrm{~mm}$ gap. The average travel speed of the electrodes is $525 \mathrm{~mm} / \mathrm{min}$ and the average wire feeding speed is 
$255 \mathrm{~cm} / \mathrm{min}$. The employed welding sequence according to the fabricator and the AISC welding guidelines by Miller (2006) for welding thick plates is summarized as follows: (a) weld one pass on one side (side-1) of the built-up box column; (b) flip the built-up box column and weld the other side (side-2) and complete weld passes 1 to 4; (c) flip again and weld side-1 and complete weld passes 2 to 7; (d) flip and weld the other side-2 and complete weld passes 5 to 7; (e) flip and weld the other side- 1 and complete weld passes pass 8 to 13; (f) flip and weld the other side- 2 and complete weld passes 8 to 13 . Another model of the welding procedure is utilized in this parametric study; it consists of two steel plates welded in the flat position with PJP welds as shown in Figure $1 b$. This model is used to simplify the parametric study in terms of parameters involving variation in the model geometry as the plate thickness and the number of passes changes. These two welding models are used to conduct a parametric study of the main parameters of the welding procedure as an approach to produce quantitative guidelines for the welding of thick steel plates.

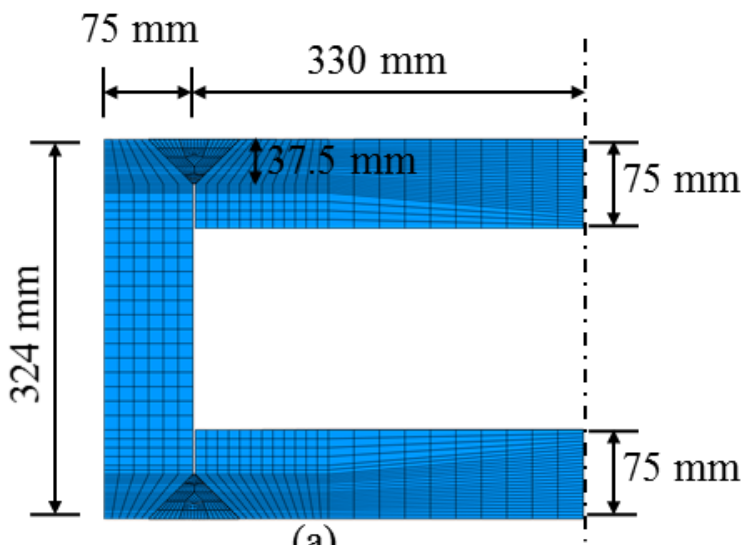

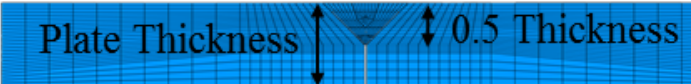

(b)

(a)

Figure 1: Cross-section of welding procedure models. a) Built-up box column, b) 2 steel plates in the flat position 


\section{Description of the Methodology Employed for the Welding Procedure Parametric study}

The parametric study of the welding procedure for thick steel plates was divided into two phases. The first phase (noted as Phase A) involves parameter variations that directly affect the heat input and the cooling rate. These parameters do not require variations of the weld geometry or sequence. The outcome of this phase is the assessment of the main parameters of the welding process and the recommendations regarding the heat input including preheat and inter-pass temperatures. In the second phase (noted as Phase B) of the parametric study additional parameters are introduced, including the steel material properties and the plate thickness variation. Additionally, in this phase the influence of the number of passes and the welding direction are included. Tables 1 and 3 summarize the main values of different parameters and the analysis models employed in this study for Phases A and B. Each phase of the parametric study is discussed in detail in Sections 3.1 and 3.2, respectively. It should be stated that the parameter variation summarized in Tables 1 and 3 was established and refined based on feedback from steel fabricators in North America. The assessment criteria for each parameter are summarized in Section 3.3.

\subsection{Phase A: parameters affecting the heat input and cooling rate}

The first phase of the parametric study was conducted using the case study model of the built-up box column shown in Figure 1a, and briefly discussed in Section 2. The two main parameters in the heat-transfer modeling are the amount of heat introduced in the welded plates (the heat input) and the rate of cooling of the plate from the welding temperature to the ambient temperature (the cooling rate). These parameters are represented in the thermo-mechanical FE model by the welding temperature, the speed of welding (electrode), as well as the preheat and the inter-pass 
temperatures. As the aim of Phase A is to compare the influence of different parameter values on the resultant residual stresses, the average base metal material properties are used through the thickness of the welded steel plates. Ten models were developed and analyzed in this phase (Table 1) using the average base metal material properties based on seventy four tensile coupon test results summarized in Ibrahim et al. (2013), the temperature-dependent mechanical properties of the base metal used in the analysis are shown in Figure 2. Additionally, Table 2 shows the temperaturedependent thermal properties of the base metal used in the analysis. The welding temperature is that of the molten pool and is a direct representation of the welding heat input. The welding temperature has to be higher than the steel melting temperature, approximately $1450^{\circ} \mathrm{C}$, to achieve fusion between the weld metal and the base metal (CWB/Gooderham-Centre, 2005; Miller, 2006); the common welding temperature is $1500^{\circ} \mathrm{C}$. Relatively high welding temperatures, i.e. 2000 and $2500{ }^{\circ} \mathrm{C}$, are used as well to account for other parameters affecting the heat input such as the welding voltage, current and wire feeding speed.

Table 1: Range of parameters investigated in Phase A of the parametric study

\begin{tabular}{cccccc}
\hline $\begin{array}{c}\text { Model } \\
\text { Number }\end{array}$ & $\begin{array}{c}\text { Welding } \\
\text { Temperature } \\
{\left[{ }^{\circ} \mathbf{C}\right]}\end{array}$ & $\begin{array}{c}\text { Welding } \\
\text { Speed } \\
{[\mathbf{m m} / \mathbf{s}]}\end{array}$ & $\begin{array}{c}{\text { Phase } \mathbf{A}^{\mathbf{a}}}^{\text {Preheat/ }} \\
\text { Inter-pass } \\
{\left[{ }^{\circ} \mathbf{C}\right]}\end{array}$ & $\begin{array}{c}\text { Base Metal } \\
\text { Material } \\
\text { Properties }\end{array}$ & $\begin{array}{c}\text { Model and } \\
\text { Studied Paths }\end{array}$ \\
\hline $\mathbf{1}^{\mathbf{b}}$ & 1500 & 10 & 20 & Avg. & \\
$\mathbf{2}$ & 2000 & 10 & 20 & Avg. & \\
$\mathbf{3}$ & 2500 & 10 & 20 & Avg. & \\
$\mathbf{4}$ & 1500 & 2.5 & 20 & Avg. & Box Column \\
$\mathbf{5}$ & 1500 & 5 & 20 & Avg. & Paths 1a to 14a \\
$\mathbf{6}$ & 1500 & 15 & 20 & Avg. & \\
$\mathbf{7}$ & 1500 & 25 & 20 & Avg. & \\
$\mathbf{8}$ & 1500 & 10 & 100 & Avg. & \\
$\mathbf{9}$ & 1500 & 10 & 250 & Avg. & \\
$\mathbf{1 0}$ & 1500 & 10 & 400 & Avg. & \\
\hline
\end{tabular}

${ }^{a}$ For all Phase A models the plate thickness is $75 \mathrm{~mm}$, number of welding passes is 13 and the base metal material properties are constant throughout the thickness.

${ }^{\mathrm{b}}$ Model 1 is also used in the study of the base metal material parameter of Phase B 


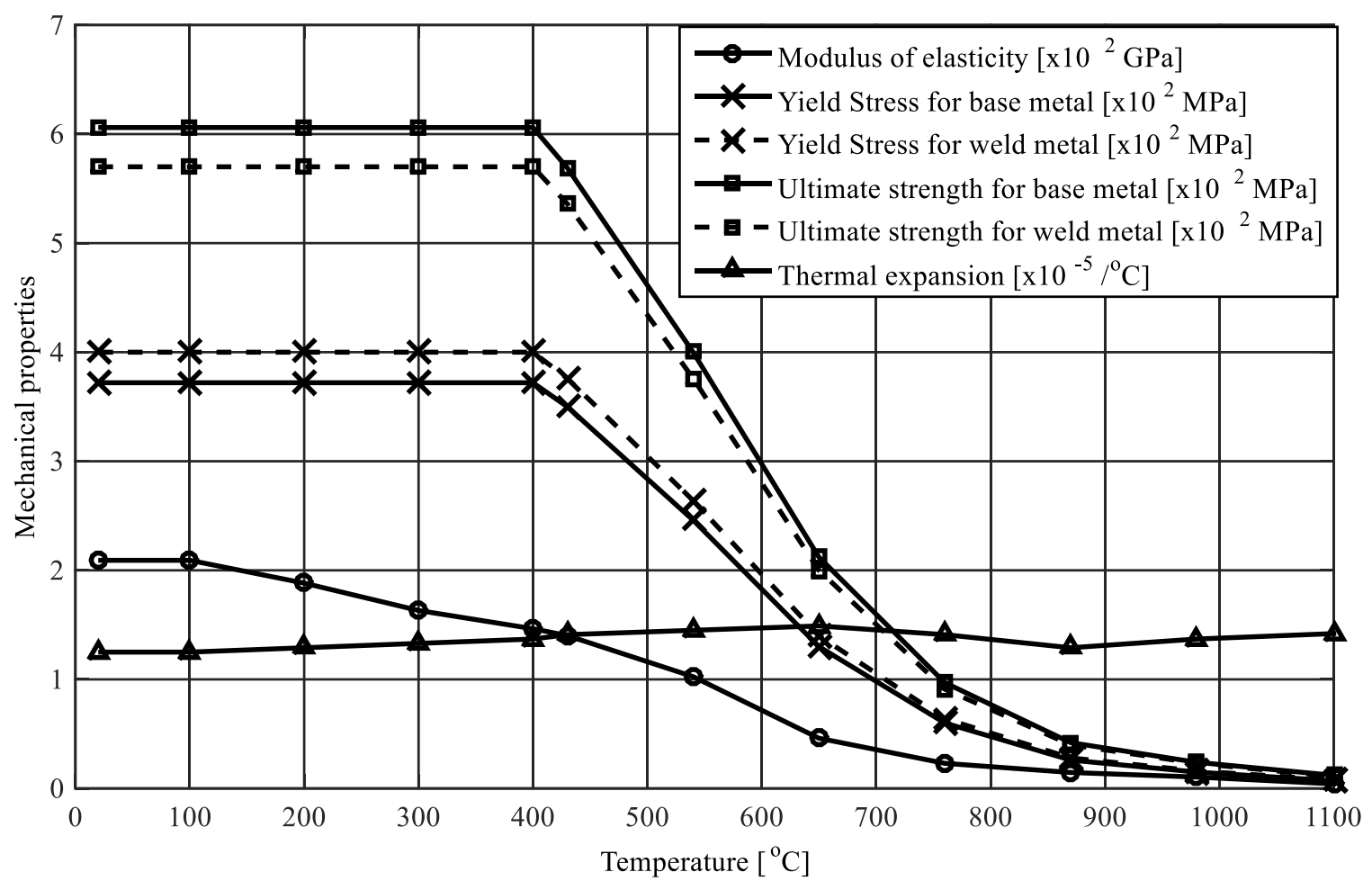

Figure 2: Material properties used in the stress analysis model at elevated temperatures based on ANSI/AISC 360-10 (2010) and Society of Fire Protection Engineers (2008)

Table 2: Steel material properties at elevated temperatures for heat transfer simulation according to Society of Fire Protection Engineers (2008)

\section{Required material properties for heat transfer}

\begin{tabular}{ccc}
\hline $\mathbf{T}\left[{ }^{\mathbf{0}} \mathbf{C}\right]$ & Thermal Conductivity $\left[\mathbf{W} / \mathbf{m} .{ }^{\mathbf{0}} \mathbf{C}\right]$ & Specific heat $\left[\mathbf{N} . \mathbf{m m} / \mathbf{K g}{ }^{\mathbf{~}} \mathbf{C}\right]$ \\
20 & 53.334 & $4.40 \mathrm{E}+08$ \\
100 & 50.67 & $4.88 \mathrm{E}+08$ \\
200 & 47.34 & $5.30 \mathrm{E}+08$ \\
300 & 44.01 & $5.65 \mathrm{E}+08$ \\
400 & 40.68 & $6.06 \mathrm{E}+08$ \\
500 & 37.35 & $6.67 \mathrm{E}+08$ \\
600 & 34.02 & $7.60 \mathrm{E}+08$ \\
700 & 30.69 & $1.01 \mathrm{E}+09$ \\
800 & 27.36 & $8.03 \mathrm{E}+08$ \\
900 & 27.3 & $6.50 \mathrm{E}+08$ \\
1000 & 27.3 & $6.50 \mathrm{E}+08$ \\
1100 & 27.3 & $6.50 \mathrm{E}+08$ \\
1200 & 27.3 & $6.50 \mathrm{E}+08$ \\
\end{tabular}


In summary, the welding temperature parameter is studied through Models 1 to 3 (Table 1). The heat input also depends on the travel speed of the electrode (Miller, 2006). In turn, this welding travel speed has a great effect on the weld penetration and the bead size. With slow welding speed the heat input increases, as does the penetration and the bead size. The disadvantages of slow welding travel speed are that it diminishes the control of the molten pool and increases the slag inclusion (Jefferson \& Woods, 1962). The average welding travel speed of the SAW procedure is approximately 10 mm/s (AWS D1.1, 2010; Miller, 2006). From Table 1, lower and higher values are used to illustrate the effect of the welding travel speed on the heat input and on the residual stresses. The welding travel speeds of 2.5 and $25 \mathrm{~mm} / \mathrm{s}$ were studied based on Model 1, and Models 4 to 7 (Table 1) in order to emphasize the effect of travel speed on the welding residual stress. However, these welding travel speeds are not practical because the slow welding travel speed decreases the control of the molten weld metal and the fast welding travel speed leads to low heat input, which in turn affects the fusion between the weld metal and base metal.

The cooling rate is the primary parameter that affects the shrinkage cracks developed in welded plates. A slow cooling rate will decrease the shrinkage stress that results in shrinkage cracks. According to Graville (1975) the cooling rate can be calculated from the heat input, the plate thickness and the preheat temperature. Preheat and inter-pass temperatures are the parameters that have the highest influence on the cooling rate. According to AWS D1.1 (2010), for ASTM A572 Gr.50 (2013) steel plates with thickness greater than $65 \mathrm{~mm}$, the preheat temperature is $110^{\circ} \mathrm{C}$ and the inter-pass temperature should not be lower than $110^{\circ} \mathrm{C}$. Moreover, the preheated area should be at a distance from the weld equal to the thickness of the thicker plate and not less than $75 \mathrm{~mm}$. The preheat and inter-pass temperatures were studied through Model 1 and Models 8 to 10. From Table 1 , these parameters vary from room temperature $\left(20^{\circ} \mathrm{C}\right)$ to $400^{\circ} \mathrm{C}$. 


\subsection{Phase B: Additional parameters}

This phase focuses on other general parameters, including those which affect indirectly the resulting residual stresses after completion of the welding procedure. Twelve models are included in this phase, in addition to Model 1 of Phase A (Tables 1 and 3). The variability of the steel's mechanical properties through the thickness of thick steel plates may have an impact on the distribution of the residual stress induced by welding. To take this into account, the mechanical properties of the steel material through the plate thickness were measured based on tensile coupon specimens from different locations in the steel plate. In the parametric study the impact of the steel mechanical properties is assessed based on the mean and standard deviation values of the elastic modulus $(E)$, the yield stress $\left(f_{y}\right)$ and the ultimate strength $\left(f_{u}\right)$. Three material profiles were based on 74 tensile coupon tests (46 through-thickness specimens and 28 specimens from the plate surface) conducted by Ibrahim et al. (2016) for different locations in the case study heavy boxcolumn. The average material properties of all the results, the lower bound (LB) (located at material near the surface of the plate) and the upper bound (UB) (located at material through the thickness of the plate) are shown in

Table 4. The base metal material properties parameter is studied through Models 1, 11 and 12 (Tables 1 and 3).

The impact of the plate thickness is also included in this modelling phase. The thicknesses used are those commonly found in current practice $25,12,19,38 \mathrm{~mm}$, as well as thicker plates 50,75 and $100 \mathrm{~mm}$. The thickness variation is studied through Models 13 to 19 (Table 3). Another important parameter is the number of welding passes. Four welding procedures were studied through Model 18 and Models 20 to 22 (Table 3); the first three are composed of 5, 13 and 20 
welding passes. The fourth welding procedure utilizes 13 welding passes with unequal welding pass sizes; such that small welding pass sizes are used for the first 10 passes and larger welding pass sizes are used for the final welding layer. Due to the variation in the model geometry for the plate thickness and the number of passes; they were studied through the model of welding two steel plates in the flat position (Figure 1b).

Table 3: Range of parameters investigated in Phase B of the parametric study

\begin{tabular}{cccccc}
\hline $\begin{array}{c}\text { Model } \\
\text { Number }\end{array}$ & $\begin{array}{c}\text { Base Metal } \\
\text { Material } \\
\text { Properties }\end{array}$ & $\begin{array}{c}\text { Base Metal } \\
\text { Thickness } \\
{[\mathbf{m m}]}\end{array}$ & $\begin{array}{c}\text { Phase } \mathbf{B}^{\mathbf{a}} \\
\text { Number of } \\
\text { Passes }\end{array}$ & $\begin{array}{c}\text { Welding Pass } \\
\text { size }\end{array}$ & $\begin{array}{c}\text { Model and } \\
\text { Studied Paths }\end{array}$ \\
\hline $\mathbf{1 1}$ & LB & 75 & 13 & Constant & Box Column \\
$\mathbf{1 2}$ & UB & 75 & 13 & Constant & Paths 1a to 14a \\
\hline $\mathbf{1 3}$ & Avg. & 12 & 13 & Variable & \\
$\mathbf{1 4}$ & Avg. & 19 & 13 & Variable & \\
$\mathbf{1 5}$ & Avg. & 25 & 13 & Variable & \\
$\mathbf{1 6}$ & Avg. & 38 & 13 & Variable & Plates welded \\
$\mathbf{1 7}$ & Avg. & 50 & 13 & Variable & in flat position \\
$\mathbf{1 8}$ & Avg. & 75 & 13 & Variable & Paths 1b to 4b \\
$\mathbf{1 9}$ & Avg. & 100 & 13 & Variable & \\
$\mathbf{2 0}$ & Avg. & 75 & 5 & Variable & \\
$\mathbf{2 1}$ & Avg. & 75 & 20 & Variable & \\
$\mathbf{2 2}$ & Avg. & 75 & $13^{+}$ & Variable & \\
\hline
\end{tabular}

${ }^{a}$ For all Phase B models the welding temperature is $1500^{\circ} \mathrm{C}$, the welding speed is $10 \mathrm{~mm} / \mathrm{s}$ and the preheat/inter-pass temperature is $20^{\circ} \mathrm{C}$.

Table 4: Values used for the Average, Lower and Upper bound material properties at $20^{\circ} \mathrm{C}$.

\begin{tabular}{|c|c|c|c|}
\hline & $\begin{array}{l}\text { Lower bound } \\
\text { Material }\end{array}$ & Average Material & $\begin{array}{l}\text { Upper bound } \\
\text { Material }\end{array}$ \\
\hline $\begin{array}{c}\text { Modulus of Elasticity }(E) \\
\text { [MPa] }\end{array}$ & 205963 & 217533 & 229103 \\
\hline Yield Stress $\left(f_{y}\right)[\mathrm{MPa}]$ & 356 & 379 & 402 \\
\hline Ultimate Stress $\left(f_{u}\right)$ [MPa] & 579 & 606 & 633 \\
\hline
\end{tabular}




\subsection{Parameter assessment criteria}

According to the preliminary results of the numerical simulation technique utilized in this study, which conform to the findings of previous research programs that involved numerical and experimental investigations (Bjorhovde et al., 1972; Pilipenko, 2001; Yang, 2008), the maximum residual tensile stresses from the welding procedure are located at the surface of the welded plates, and gradually decrease through the thickness until reaching the center of the steel plate. Consequently, the temperature and residual stress results of each of the 22 models discussed in Sections 3.1 and 3.2 (Tables 1 and 3) were obtained at the plate surface after each welding pass at all the locations shown in Figures 3 and 4 in the transverse and longitudinal directions, respectively. These paths represent possible regions for the peak tensile residual stresses according to the stress distribution results. The assessment of the results from each parameter is based on two criteria; the first is the effect of the parameter on the stress distribution and peak tensile stresses at the plate surface for all the paths mentioned in Figures 3 and 4, as well as through the plate thickness. The second criterion is related to the critical crack sizes at the plate surface, after each welding pass, for a probability of crack initiation of $5 \%$ based on the statistical assessment of the fracture toughness as discussed in Ibrahim et al. (2017). Figure 5 shows the relation between the applied stress, the crack size and the probability of this crack to initiate at $21^{\circ} \mathrm{C}$. In this example, if the probability limit of crack initiation is set to $5 \%$ and the applied stress is assumed as $600 \mathrm{MPa}$ then the critical crack size will be $7 \mathrm{~mm}$. Through this assessment process, the impact of each parameter on the output stress distribution and on the temperature distribution throughout the welding procedure has been taken into account. 


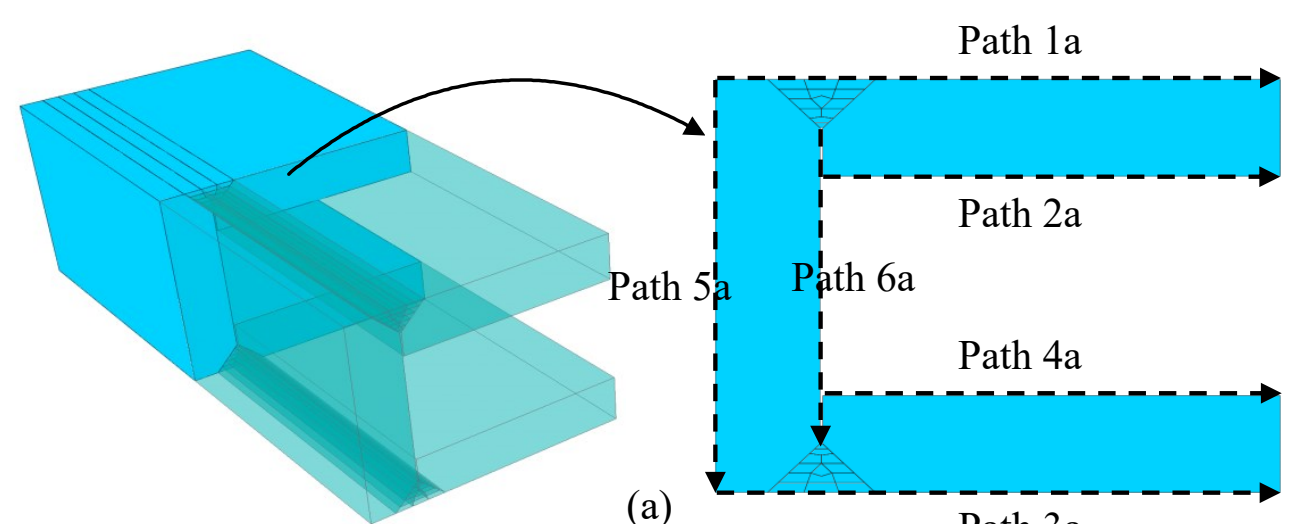

(a)

Path 3a

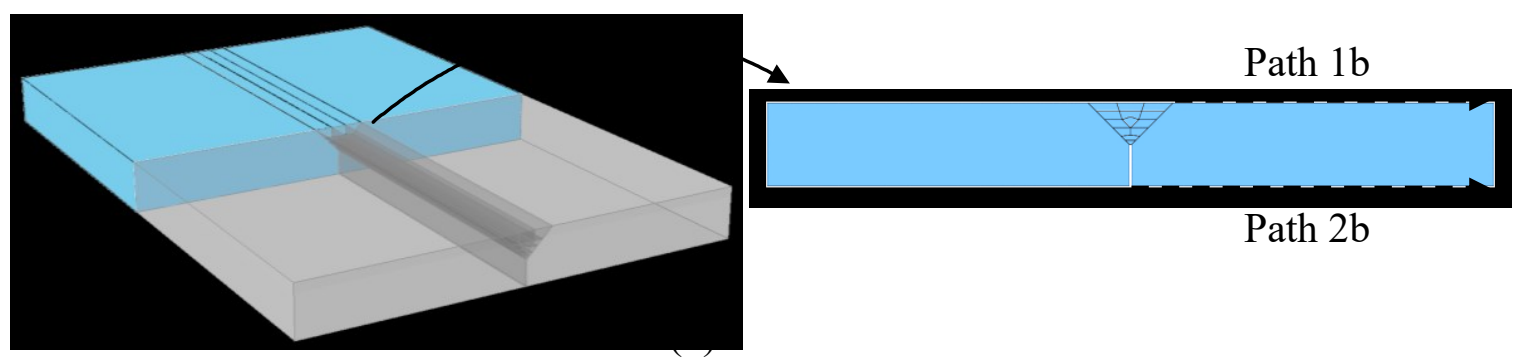

Figure 3: Studied paths in the transverse direction for, a) Built-up heavy box column model, b) Plates welded in flat position model. 

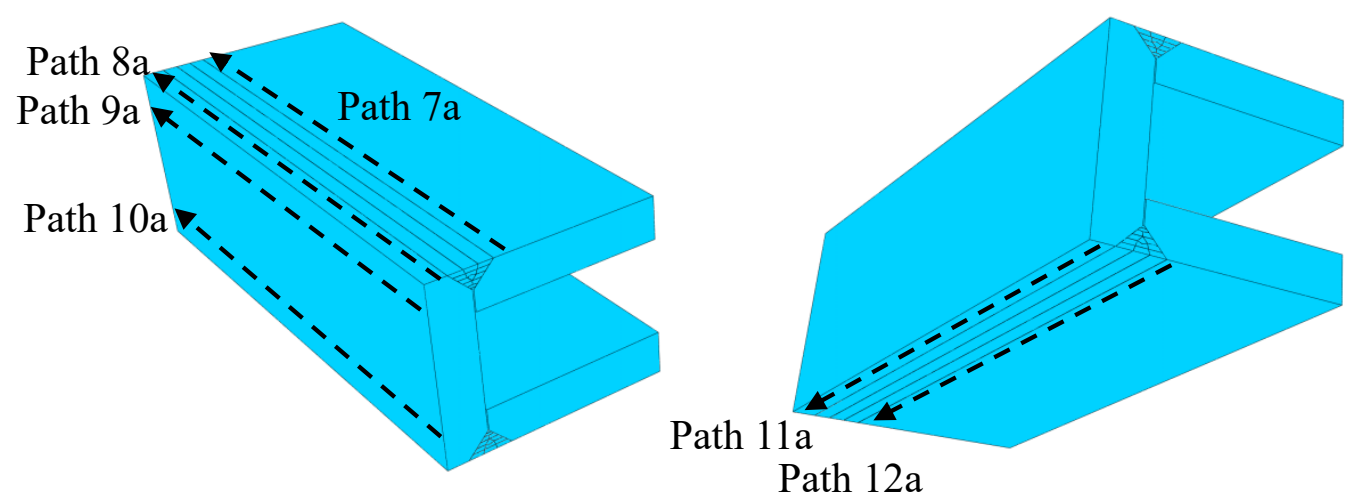

Path 12a
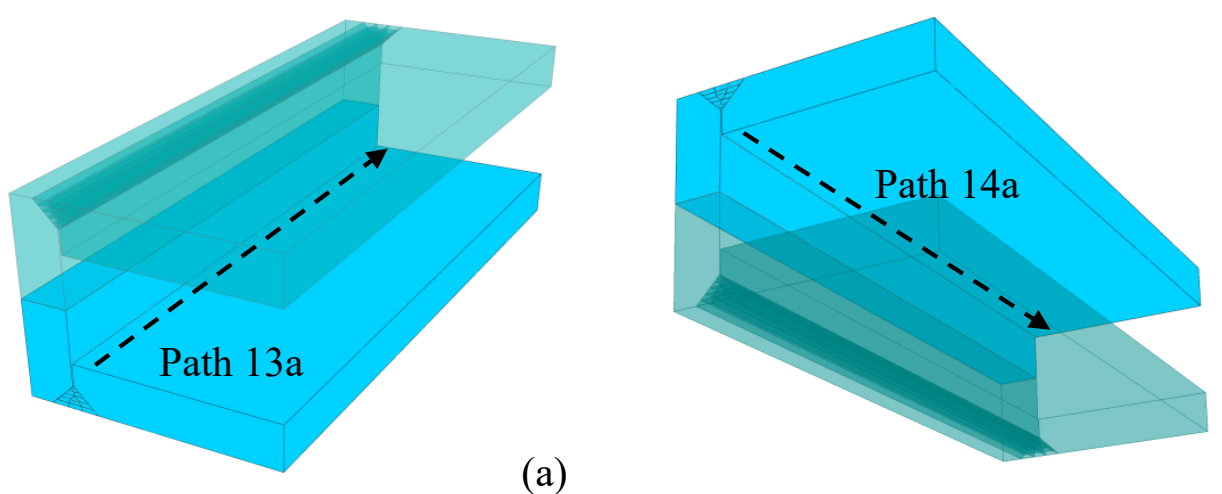

(a)
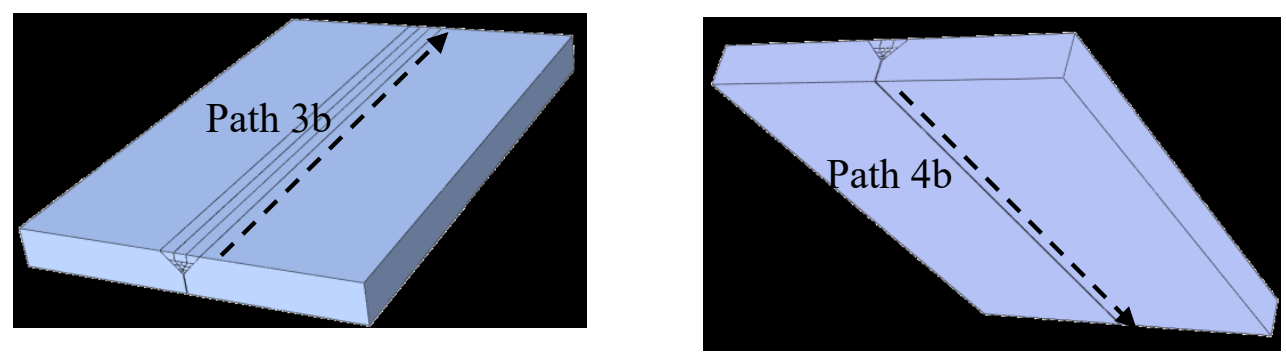

(b)

Figure 4: Studied paths in the longitudinal direction for, a) Built-up heavy box column model, b)

Plates welded in flat position model. 


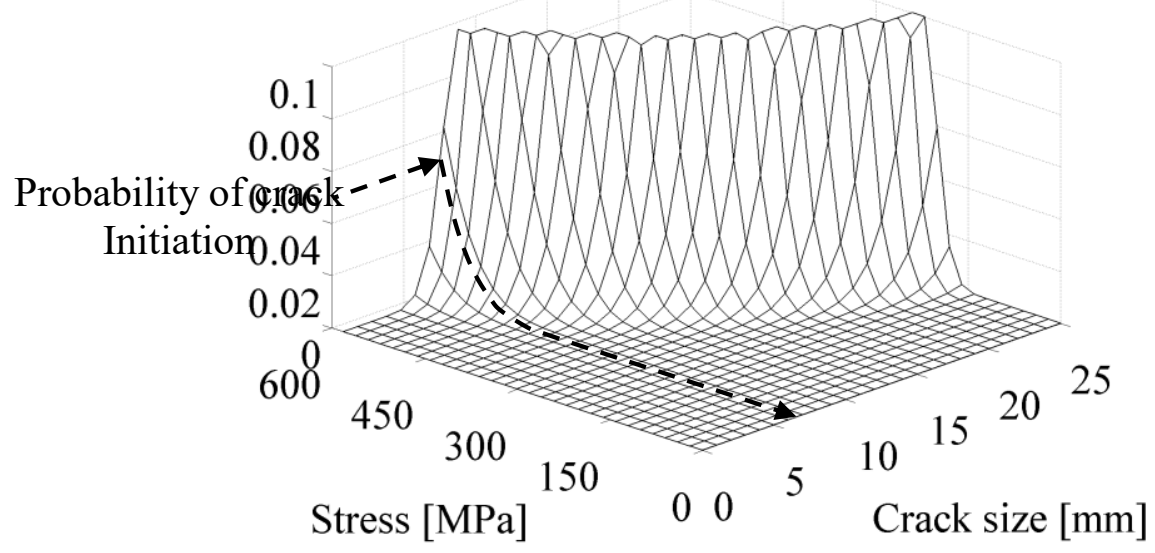

Figure 5: Relation between the applied stress, the crack size and the probability of the crack to initiate (adapted from Ibrahim et al. (2017)).

\section{$4 \quad$ Results and Discussion}

The results of the stress and temperature distributions for each of the 22 models (Tables 1 and 3 ) of the parametric study were obtained at the locations shown in Figures 3 and 4, respectively. Each parameter was assessed according to Section 3.3. Sections 4.1 and 4.2 summarize the results of Phases A and B, respectively. Section 4.3 provides recommendations for the welding procedures of thick steel plates (greater than 50mm thick), to improve the residual stress distribution and to reduce the probability of crack initiation in welded thick steel plates.

\subsection{Discussion for Phase A results: Welding Procedure Parameters}

Phase A of the parametric study primarily focuses on the heat input and cooling rate of the welding procedure. The aim of this phase is to compare the commonly used values for the welding process parameters for thick steel plates with other suggested values for the welding temperature, travel speed and preheat/inter-pass temperature. 


\subsubsection{Welding temperature}

The welding temperature is a direct representation of the heat input in the numerical model; temperatures of 1500,2000 and $2500^{\circ} \mathrm{C}$ were considered. It is worth mentioning that the $2500^{\circ} \mathrm{C}$ welding temperature was only used as an academic value to demonstrate the effect of high heat input on the resulting residual stresses. Figures $6 \mathrm{a}$ and $6 \mathrm{~b}$ show the transverse residual stresses through the Path-5a (Figure 3a) (in the direction perpendicular to the welding line) for the welding temperatures $1500^{\circ} \mathrm{C}$ and $2000^{\circ} \mathrm{C}$, respectively. The graphs illustrate that the residual stress increases with each welding pass such that the maximum residual stress is that after the last welding pass. It can be concluded from the graphs that with a $500^{\circ} \mathrm{C}$ increase in welding temperature the residual transverse stress at the plate surface near the welding area increases by $20 \%$. For a welding temperature of $2500^{\circ} \mathrm{C}$ the analysis stopped after the fifth welding pass due to numerical limitations given the high heat input, and as such a full set of results could not be presented. Figure $6 \mathrm{c}$ shows the critical longitudinal surface discontinuity size at the welded plate surface after each welding pass for a probability of crack initiation of $5 \%$ according to the resulting stress levels at all the studied paths (Figures $3 \mathrm{a}$ and $4 \mathrm{a}$ ). It is worth mentioning that the critical crack size of $1000 \mathrm{~mm}$ reflects that it is unlikely for an actual crack to be critical according to the resulting stresses, i.e. a high critical crack size means low residual stresses resulting from the corresponding welding procedure. For the early welding stages there is a significant difference in the allowed discontinuity size for the commonly used welding temperature $\left(\mathrm{t}_{\mathrm{w}}=1500^{\circ} \mathrm{C}\right)$ and for a higher welding temperature (i.e., $\mathrm{t}_{\mathrm{w}}=2000^{\circ} \mathrm{C}$ ). For the final welding stages, there is no significant difference in the critical discontinuity sizes $(30 \mathrm{~mm})$ between the welding temperatures that were investigated. In conclusion, the residual tensile stress developed at the end of the welding procedure produce the smallest critical discontinuity size. 


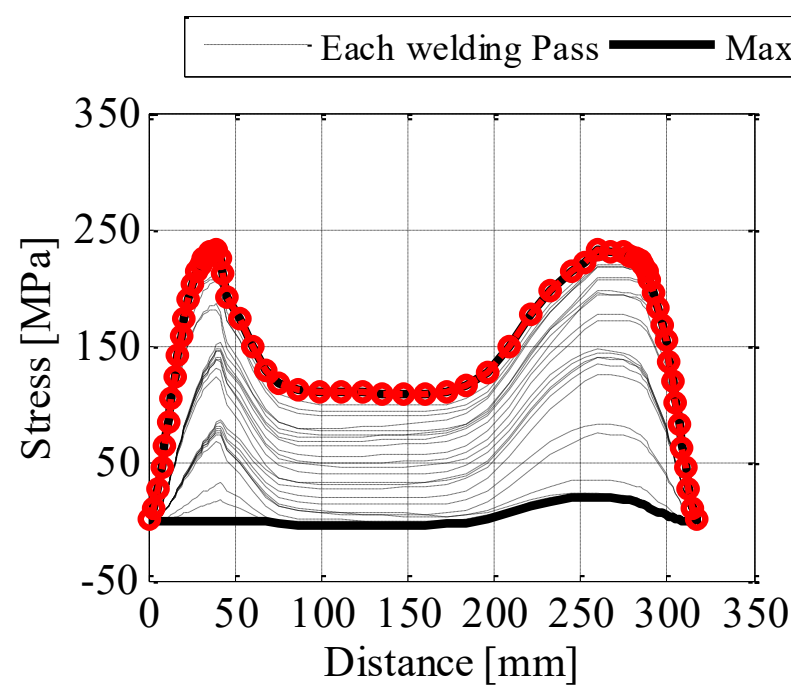

(a) Transverse stress distribution at Path5a for welding temperature $1500^{\circ} \mathrm{C}$

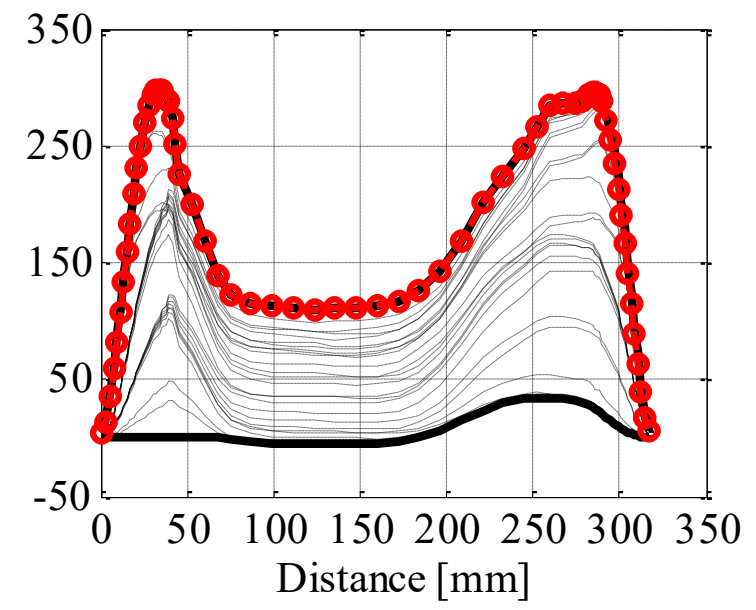

(b) Transverse stress distribution at Path5a for welding temperature $2000^{\circ} \mathrm{C}$

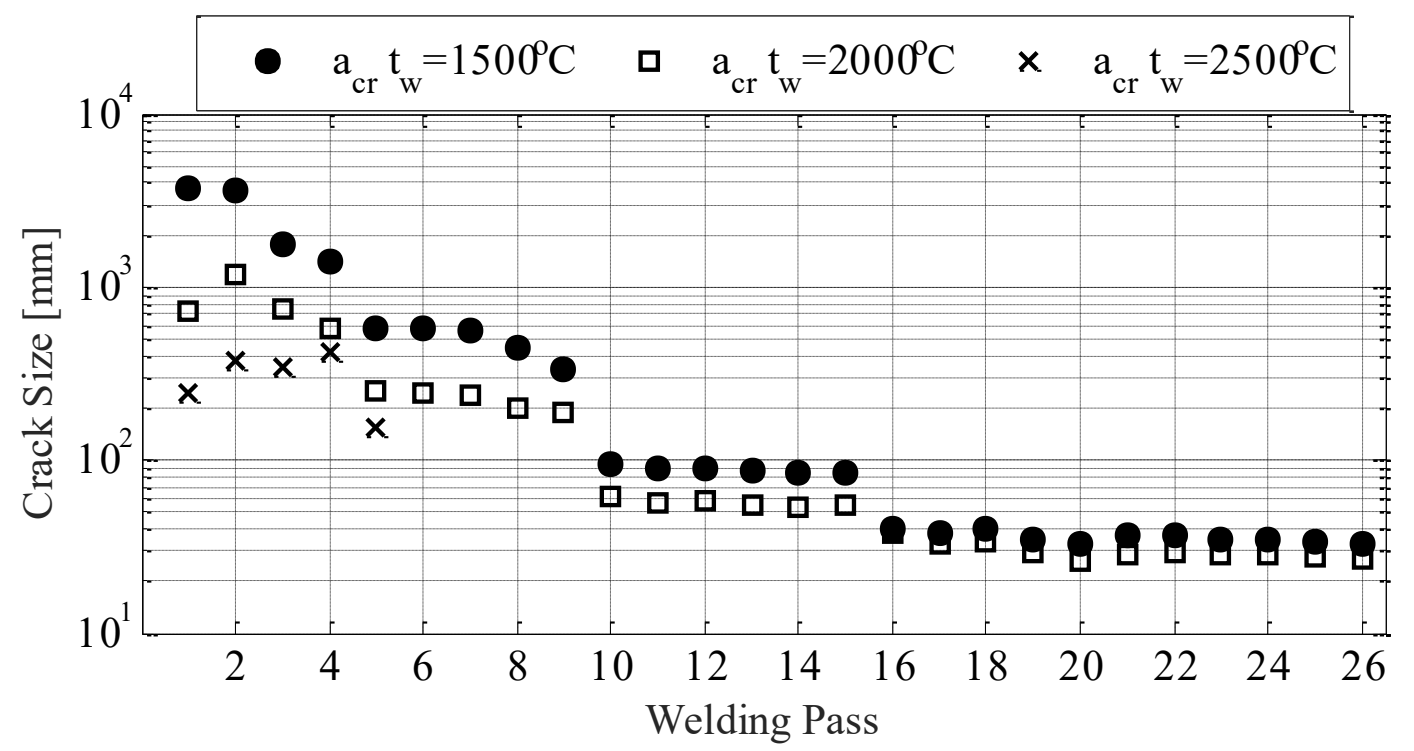

(c) Critical crack size for longitudinal crack at 5\% probability of crack initiation

Figure 6: Effect of the welding temperature on the residual stress distribution and the critical crack size

\subsubsection{Welding travel speed}

The heat input is inversely proportional to the welding (electrode) travel speed. Based on feedback from the steel industry, for the automated SAW process, the fastest practical welding travel speed 
is $15 \mathrm{~mm} / \mathrm{s}$ and the slowest is $5 \mathrm{~mm} / \mathrm{s}$. In the present paper, the models were run with welding speeds of $2.5,5,10,15$ and $25 \mathrm{~mm} / \mathrm{s}$. Figures $7 \mathrm{a}$ and $7 \mathrm{~b}$ show the transverse residual stresses resulting from the fastest practical welding travel speed $\mathrm{V}_{\mathrm{w}}=15 \mathrm{~mm} / \mathrm{s}$ and the slowest practical welding speed $\mathrm{V}_{\mathrm{w}}=5 \mathrm{~mm} / \mathrm{s}$ along Path-1a (Figure $3 \mathrm{a}$ ). It is worth mentioning that the maximum tensile stresses at the base metal surface do not occur at the plate edge in contact with the weld due to the lack of constraints at this location at the beginning of the welding procedure. Instead, the maximum tensile stresses at the base metal surface occur at a distance from the weld where constraints are higher than near the edges. In addition, with an increase in the welding travel speed (decreasing the heat input), the transverse residual stresses have increased. However, the width of the area of the base metal subjected to high tensile stresses has decreased. This is due to the fact that low heat input does not allow the heat energy to flow deep into the base metal, while this is provided when using slow welding travel speed and high heat input. Figure $7 \mathrm{c}$ demonstrates the critical longitudinal discontinuity sizes at the plate surface for each welding travel speed that was considered after each welding pass for a $5 \%$ probability of crack initiation. The figure is based on the resulting stress levels at all the studied paths (Figures 3a and 4a). The critical discontinuity size at early welding stages is high for $V_{w}=25 \mathrm{~mm} / \mathrm{s}$ compared to that of $V_{w}=10 \mathrm{~mm} / \mathrm{s}$ and $V_{w}=15 \mathrm{~mm} / \mathrm{s}$. For the slowest welding travel speeds used in this study, i.e. $\mathrm{V}_{\mathrm{w}}=5 \mathrm{~mm} / \mathrm{s}$ and $\mathrm{V}_{\mathrm{w}}=2.5 \mathrm{~mm} / \mathrm{s}$, the critical discontinuity size at the plate surface at early welding stages was the lowest. After the welding process had finished, the critical discontinuity size was equal to $30 \mathrm{~mm}$ (Figure 7c) regardless of the employed welding travel speed. High welding travel speed such as $V_{\mathrm{w}}=25 \mathrm{~mm} / \mathrm{s}$ can result in lack of fusion (Miller, 2006). From these results it can be implied that using the fastest welding travel speed, at which fusion is still assured, provides the benefit of a narrow high tensile stressed area in the base 
metal, which decreases the likelihood of the presence of a discontinuity in this area, while the slowest welding travel speed provides lower tensile stress values at a wider area in the base metal.

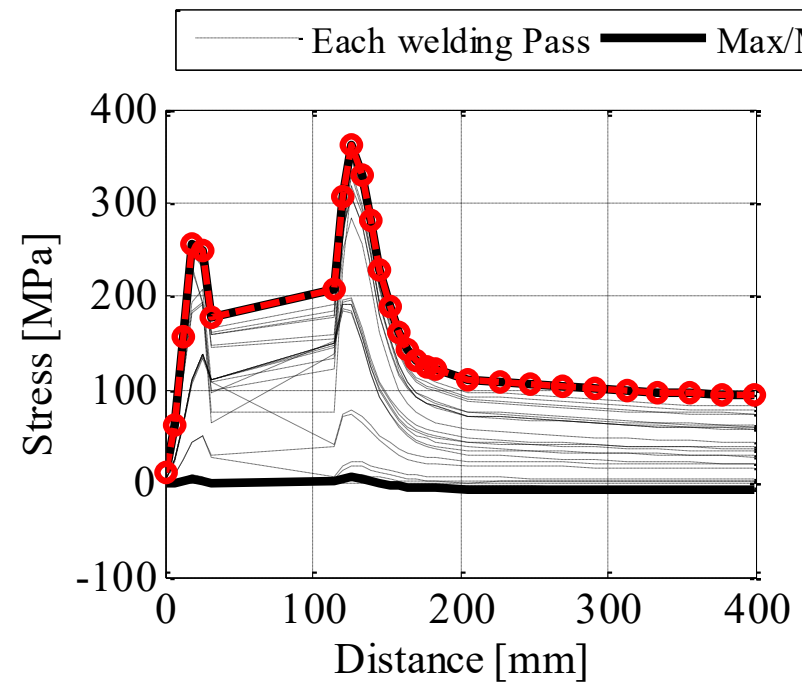

(a) Transverse stress distribution at Path-1a for welding speed $15 \mathrm{~mm} / \mathrm{s}$

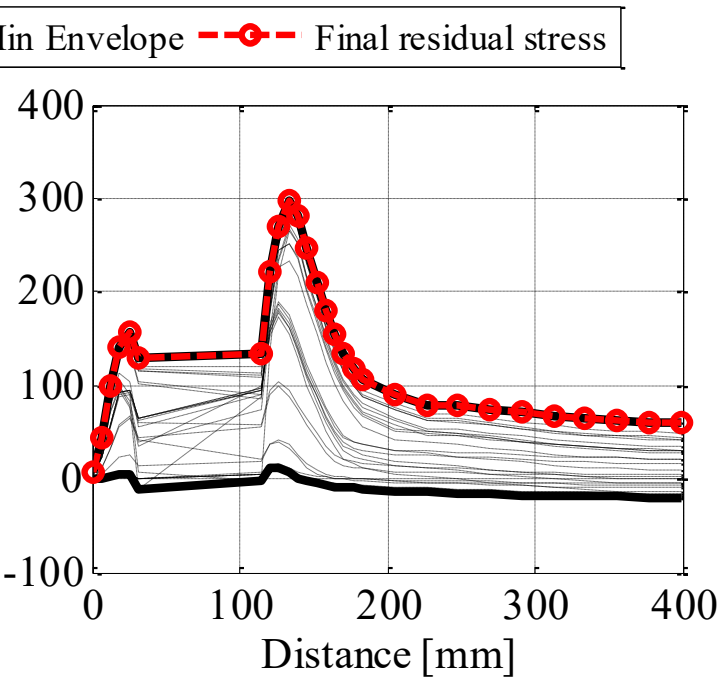

(b) Transverse stress distribution at Path-1a for welding speed $5 \mathrm{~mm} / \mathrm{s}$

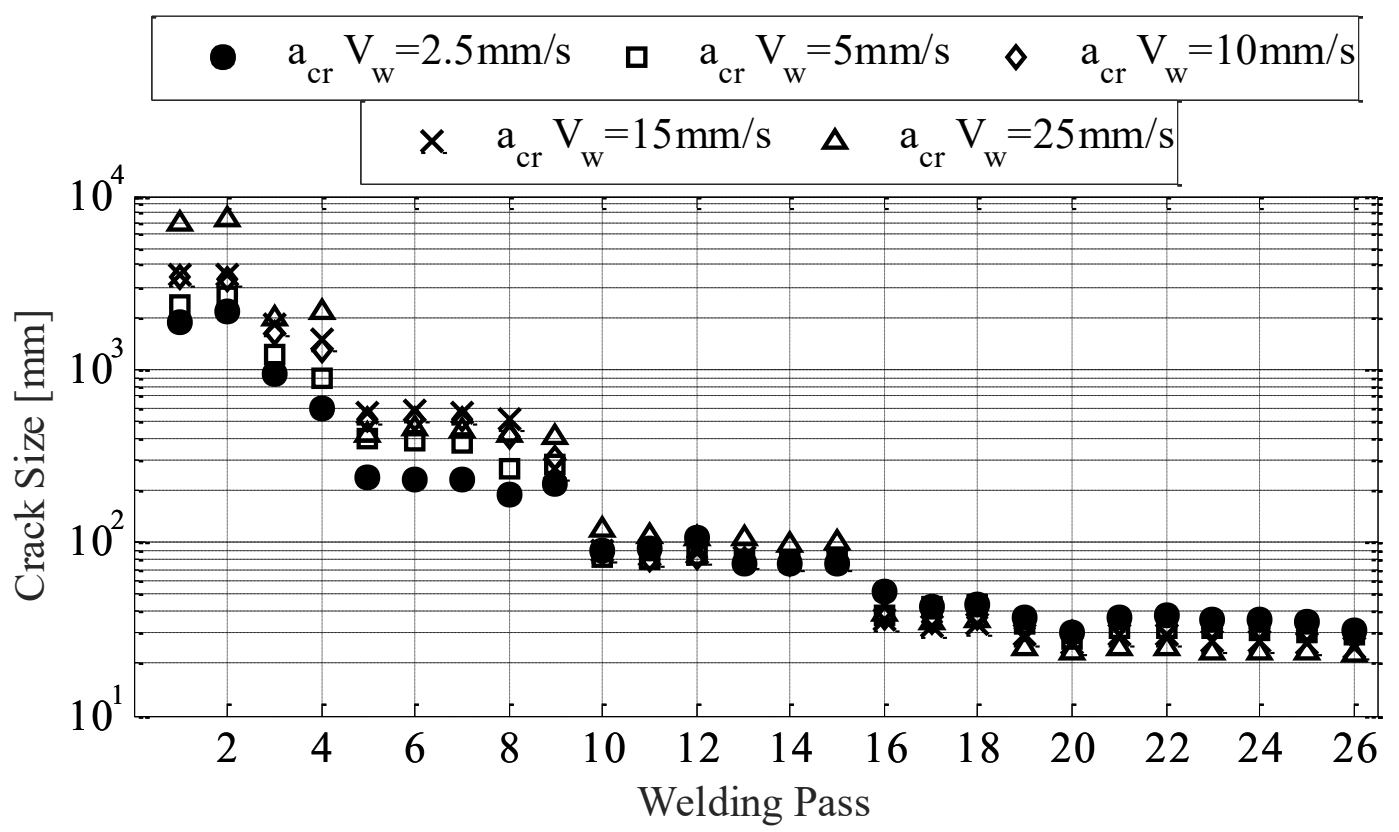

(c) Critical crack size for a longitudinal crack at 5\% probability of crack initiation

Figure 7: Effect of the welding travel speed on the residual stress distribution and the critical crack size 


\subsubsection{Preheat/inter-pass temperatures}

The last parameter, which was investigated as part of Phase A, is the preheat/inter-pass temperature. The base metal is preheated to a specified temperature in the vicinity of the welding area before the welding procedure starts. This temperature is maintained at these regions throughout the welding procedure. Figure 8 illustrates the transverse stress distribution, along Path-5a (Figure 3a), for the case of no preheating $\left(20^{\circ} \mathrm{C}\right)$ and then for preheat/inter-pass temperatures $\left(t_{p}\right)$ of $150^{\circ} \mathrm{C}, 225^{\circ} \mathrm{C}$ and $400^{\circ} \mathrm{C}$.

The maximum stress distribution also occurs after the final welding pass. Using preheat/inter-pass temperature directly affects the stress distribution in the base metal, because it decreases the amplitude of the heating cycles through the welding process as well as the cooling rate. The stress distributions shown in Figure 8 are practically the same regardless of the preheat/inter-pass temperatures of $150^{\circ} \mathrm{C}, 225^{\circ} \mathrm{C}$ and $400^{\circ} \mathrm{C}$; the peak transverse stress decreased by $25 \%$ as a result

of applying $t_{p}$. Figure 9 shows the critical discontinuity sizes in the transverse direction for the different preheat/inter-pass temperatures after each welding pass according to the resulting stress levels at all the studied paths (Figures $3 \mathrm{a}$ and $4 \mathrm{a}$ ). By applying a preheat/inter-pass temperature, the critical crack sizes become longer. However, the difference between the critical crack sizes for $t_{p} 150^{\circ} \mathrm{C}, 225^{\circ} \mathrm{C}$ and $400^{\circ} \mathrm{C}$ is not significant; therefore, the minimum preheat/inter-pass temperature of $150^{\circ} \mathrm{C}$ currently suggested by AWS D1.1 (2010) is sufficient to achieve the lowest stress distribution. 


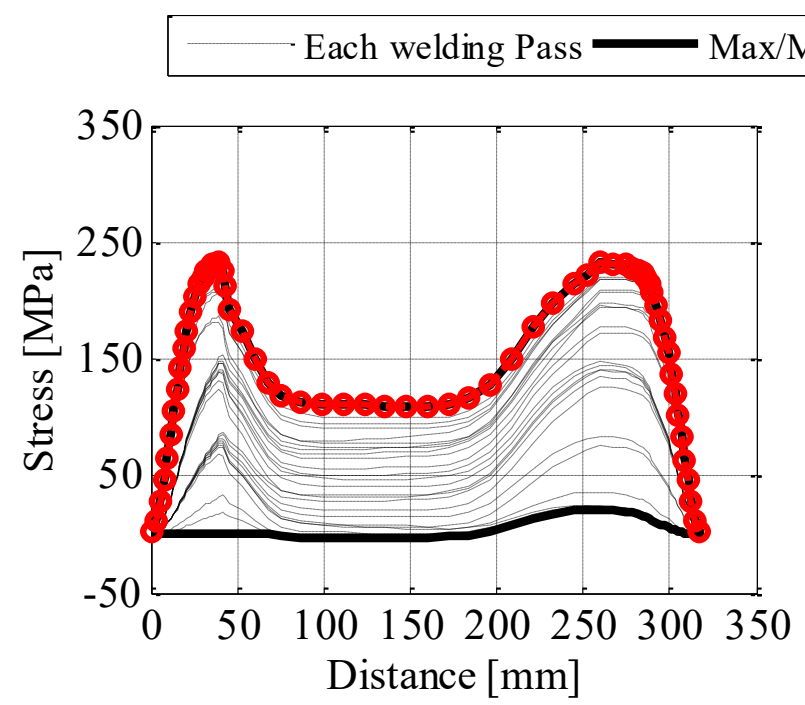

(a) Transverse stress distribution at Path-5a for no Preheat/inter-pass temp.

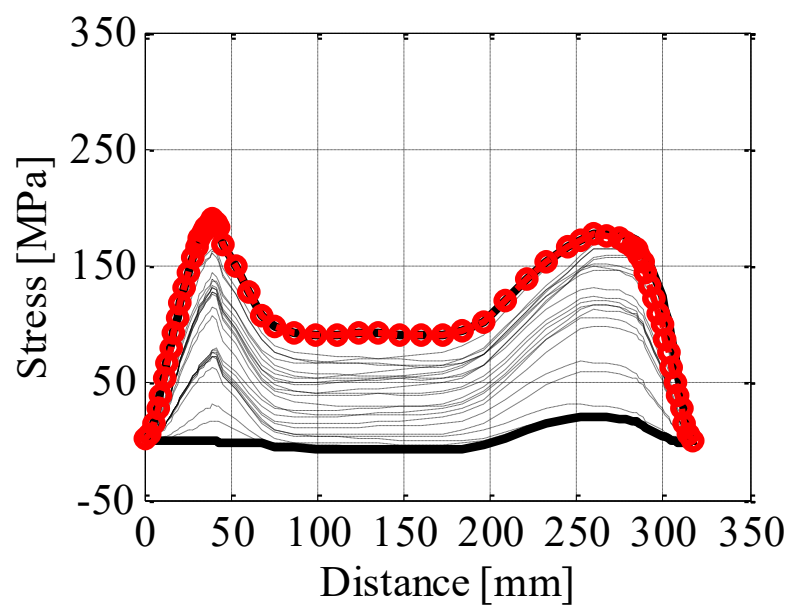

(c) Transverse stress distribution at Path-5a for Preheat/inter-pass temp. $225^{\circ} \mathrm{C}$

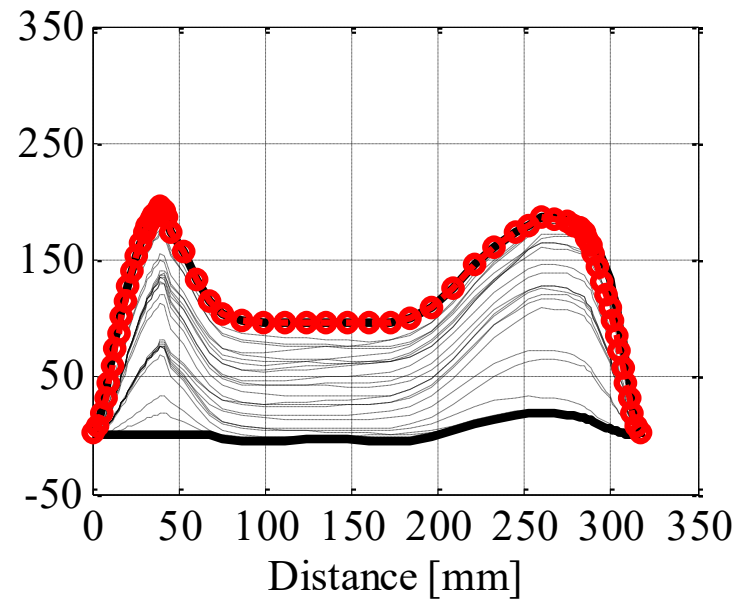

(b) Transverse stress distribution at Path-5a for Preheat/inter-pass temp. $150^{\circ} \mathrm{C}$

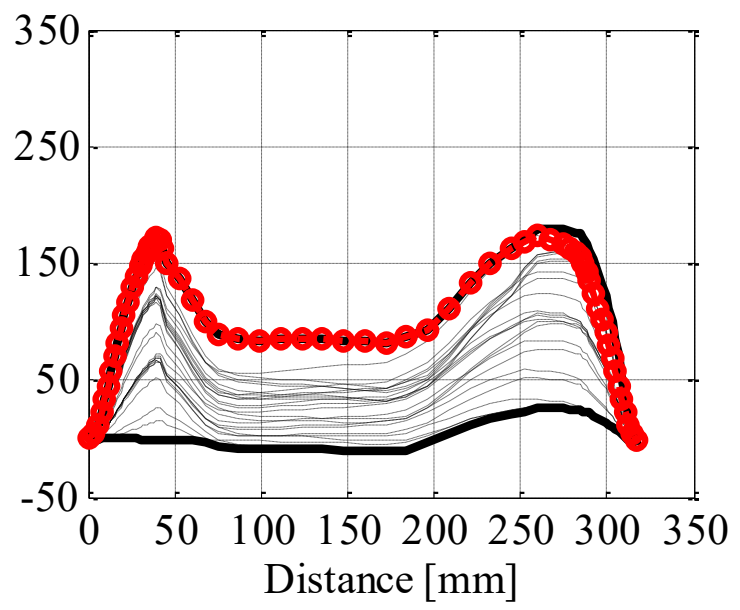

(d) Transverse stress distribution at Path-5a for Preheat/inter-pass temp. $400^{\circ} \mathrm{C}$

Figure 8: Effect of the preheat/inter-pass temperature on the residual stress distribution. 


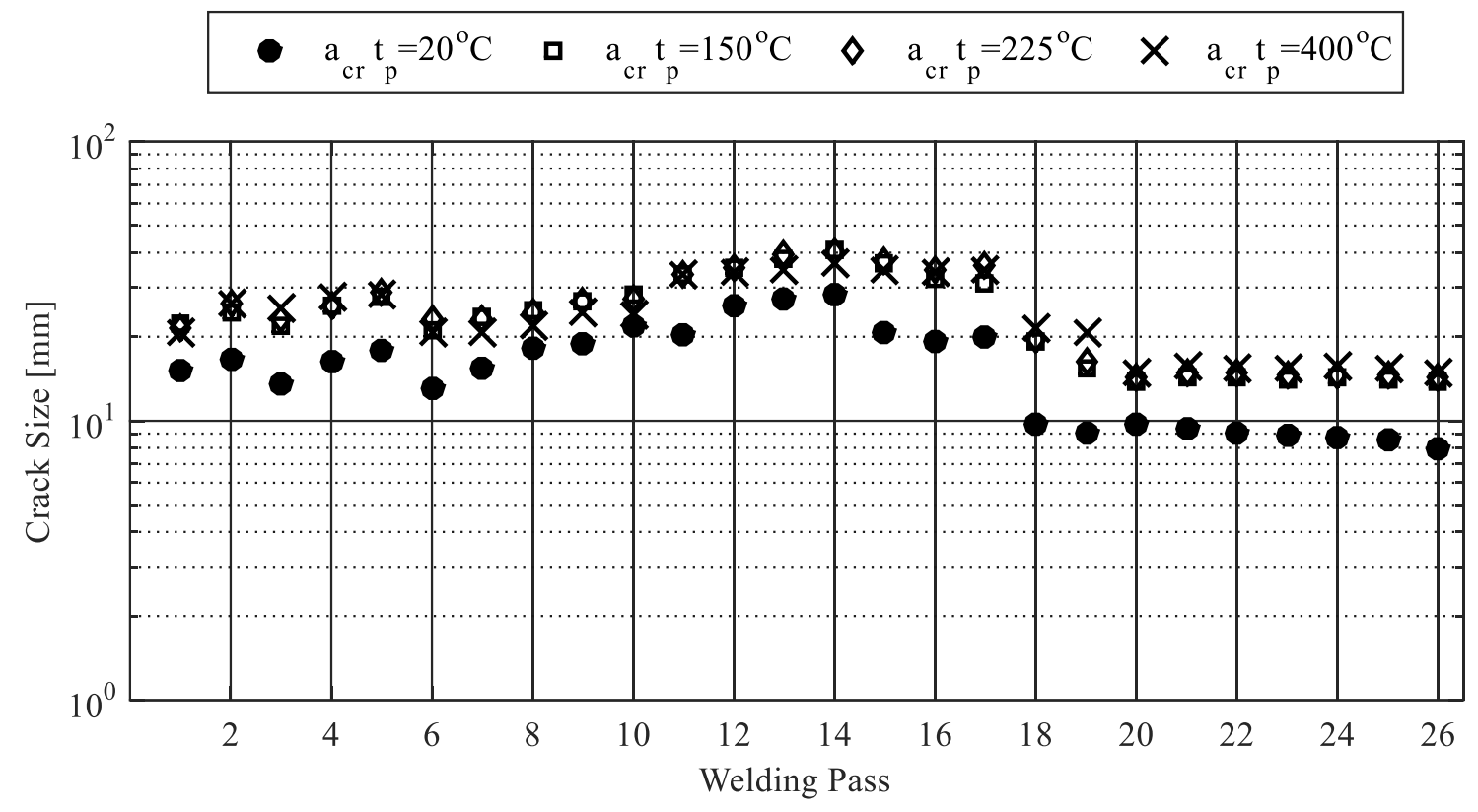

Figure 9: Effect of the preheat/inter-pass temperature on the critical transverse crack size at 5\% probability of initiation.

\subsection{Discussion for Phase B results: Geometry and Material Parameters}

In Phase B of the study the general properties in terms of geometry and material of the welded assembly are studied with the aim to detect the properties that have the most influential contribution to the residual stress distributions and the probability of crack initiation.

\subsubsection{Mechanical properties of the base metal}

Due to the variability of the mechanical properties of thick steel plates (see Ibrahim et al. (2016)), the material model was defined as having the average mechanical properties of the test results, the lower bound (LB) properties and the upper bound (UB) properties as shown in

Table 4, throughout the plate thickness. Figures 10a and 10b show the transverse stress distribution of the LB and the UB material models along Path-1a (Figure 3a). From these figures, the difference 
in stress distributions is not significant; the more ductile material based on specimens taken near the case study plate surface produced a slightly lower stress distribution than the brittle material property based on specimens taken through the thickness of the case study plate. Figure 10c shows the critical longitudinal crack size for a 5\% probability of crack initiation according to the resulting stress levels at all the studied paths (Figures 3a and 4a). Similar observations hold true regardless of the employed material model. It can be concluded that the mechanical properties of the base metal material, within the range considered, have a negligible impact on the residual stress distribution and probability of crack initiation. As such, it seems acceptable to neglect the variability of the mechanical properties through the thickness of a steel plate when studying the impact of the welding procedure on the residual stresses and probability of crack initiation. 


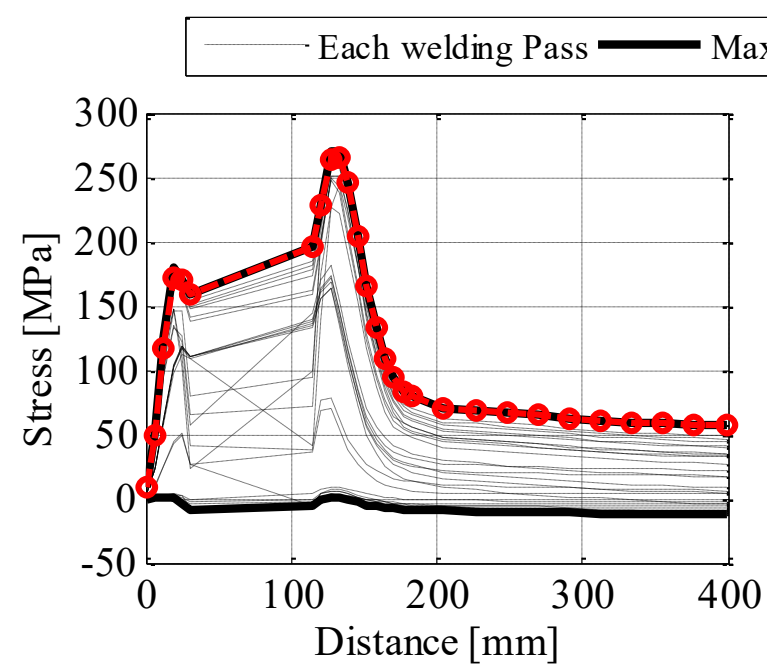

(a) Transverse stress distribution at Path-1a for lower bound material properties

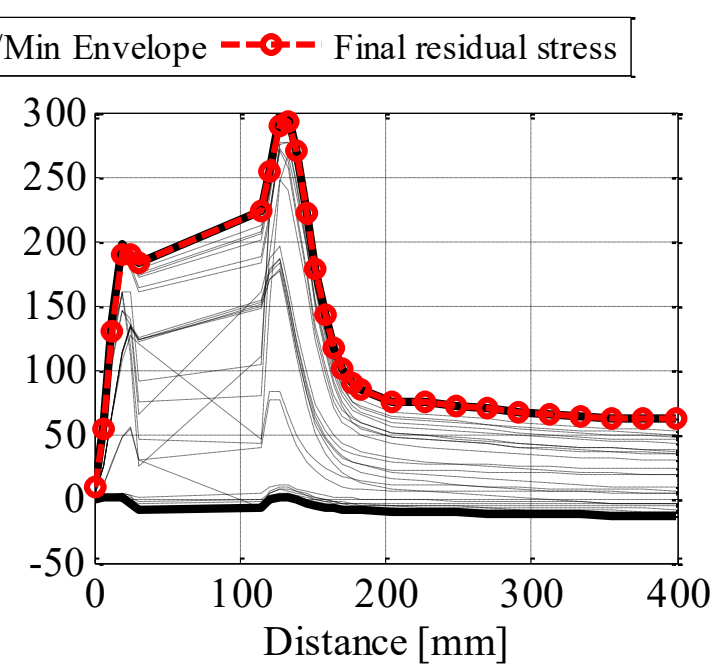

(b) Transverse stress distribution at Path1a for upper bound material properties

- $a_{c r}$ (LB material) $\quad a_{c r}$ (Ave. material) $\diamond \quad a_{c r}$ (UB material)

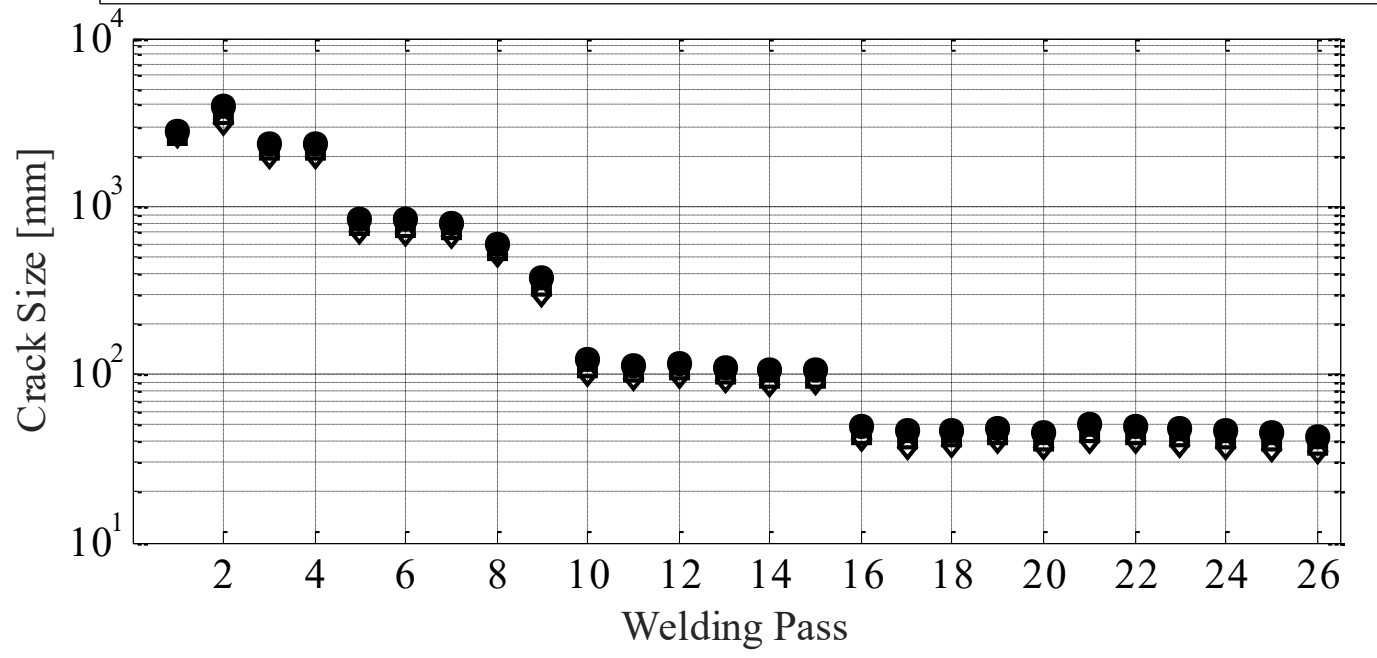

(c) Critical crack size for longitudinal crack at 5\% probability of crack initiation

Figure 10: Effect of the base metal mechanical properties on residual stress distribution and the critical crack size.

\subsubsection{Base metal plate thickness}

Furthermore, the impact of the plate thickness on the welding residual stresses and critical crack sizes is studied for the flat plate model. Figure 11 shows the transverse stress distributions for the plate thicknesses of 12, 25, 50 and 100mm along Path-1b (Figure 3b). 


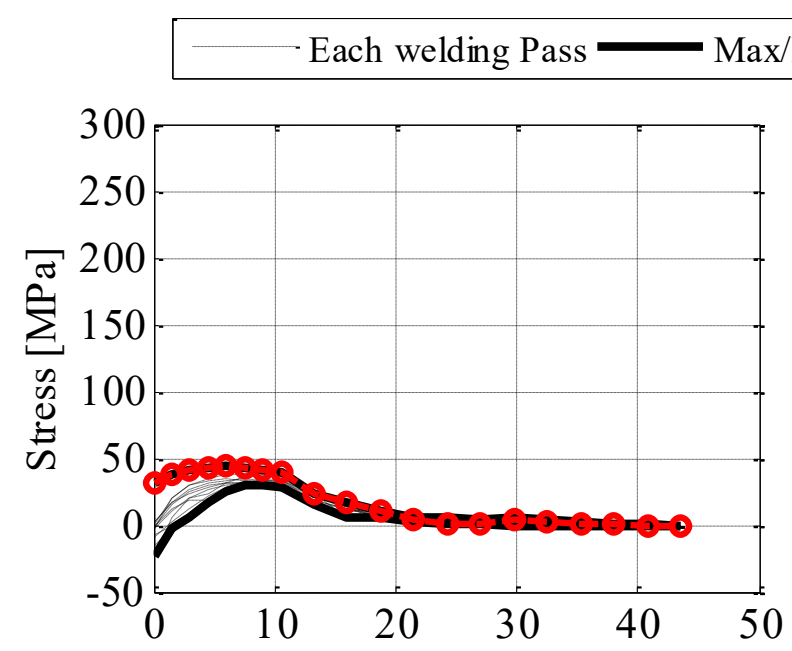

(a) Transverse stress distribution at Path-1b for plate thickness $12 \mathrm{~mm}$

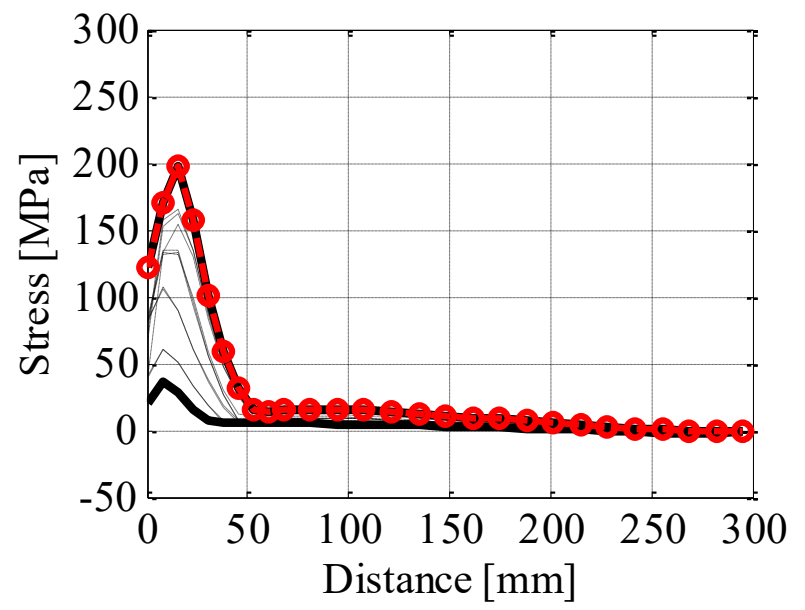

(c) Transverse stress distribution at Path-1b for plate thickness $50 \mathrm{~mm}$

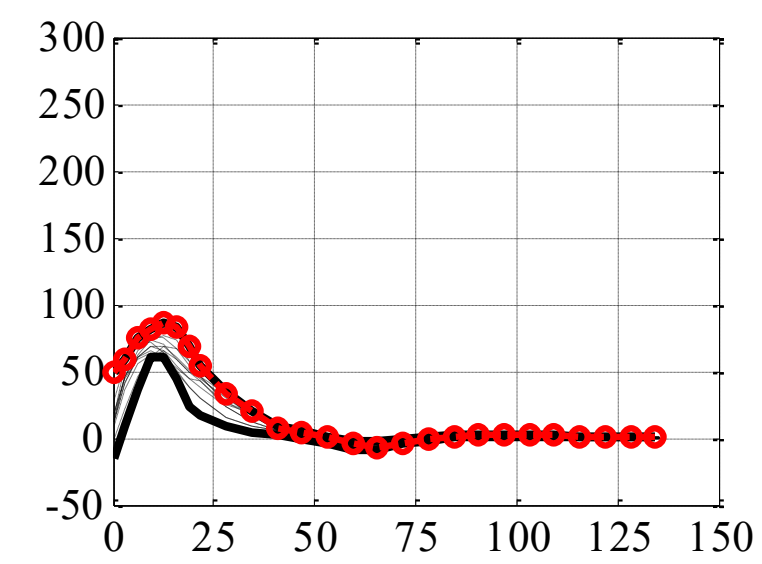

(b) Transverse stress distribution at Path-1b for plate thickness $25 \mathrm{~mm}$

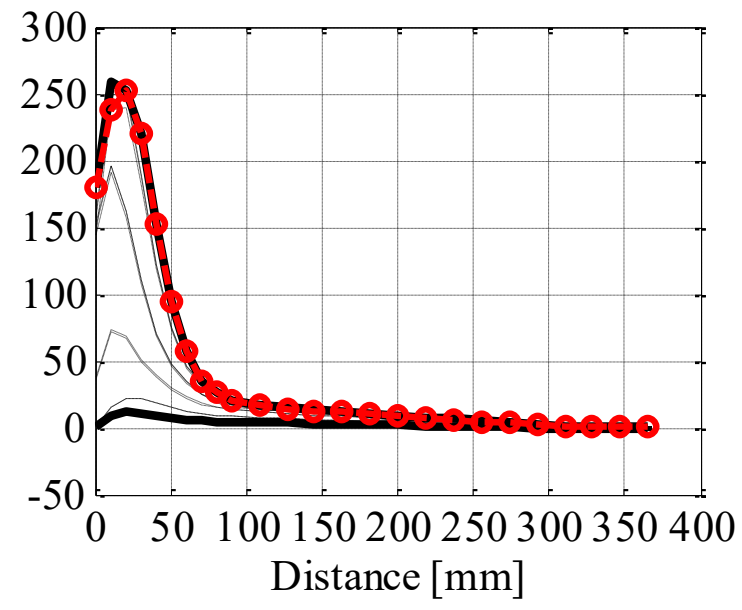

(d) Transverse stress distribution at Path-1b for plate thickness $100 \mathrm{~mm}$

Figure 11: Effect of plate thickness on the transverse residual stress distribution due to welding

The same welding procedure was applied for all plates with the same number of passes (13) but with a relative pass size based on the plate thicknesses ratio; such that all plate models experience the same number of heat cycles irrespective of thickness while using a corresponding heat input for each welding procedure, being proportional to the plate thickness. Residual stresses and crack initiation are more critical for thick plates than thin plates due to the higher restraints provided by the plate thickness. For example, a 50mm thick steel plate has a maximum tensile residual stress 
of $200 \mathrm{MPa}$ after welding, while that of a $25 \mathrm{~mm}$ thick plate is less than $100 \mathrm{MPa}$, as shown in Figure 11. However, thin plates experience more deformation during the welding procedure than thick plates (Pilipenko, 2001) as shown in Figure 12. From these figures, it can be clearly shown that the recommended welding procedures for $25 \mathrm{~mm}$ thick plates currently available in AWS D1.1 (2010) should not be extrapolated for use with thick plates.

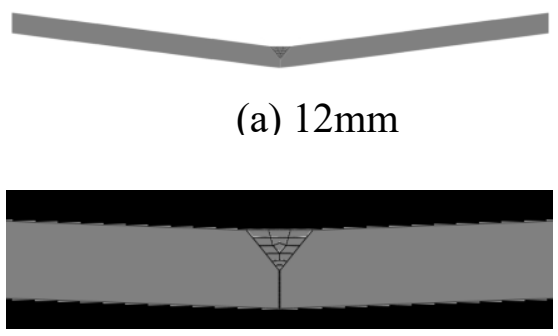

(c) $50 \mathrm{~mm}$

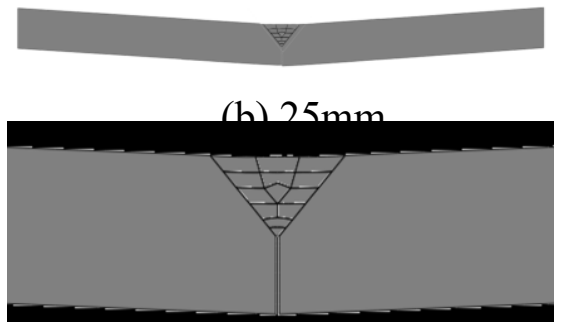

(d) $100 \mathrm{~mm}$

Figure 12: Residual deformations from the welding procedure for steel plates of thicknesses.

The base metal plate thickness also has a direct effect on the steel plate through-thickness stress distribution. Figure 13 shows the transverse and longitudinal stress distributions, after the welding procedure has been completed, through the thickness of the plates and at a distance from the welded area equal to $20 \%$ of the plate thickness $(t)$; where the peak tensile residual stresses are located based on previous analyses. The transverse stress distributions demonstrate an increase in the stress variation through the plate thickness with the increase in thickness. For the $12 \mathrm{~mm}$ thick plate the transverse stress at the plate surface was $40 \mathrm{MPa}$ and the through-thickness stress was $25 \mathrm{MPa}$, while for the $100 \mathrm{~mm}$ thick plate the transverse stress at the plate surface was $240 \mathrm{MPa}$ and the through-thickness stress was -100MPa. The reason for this is that with the increase in thickness the heating and cooling process, associated with the welding procedure, becomes less uniform through the thickness of the plate. 


\begin{tabular}{|llll|}
\hline $\boldsymbol{0}$ & $\mathrm{t}=100 \mathrm{~mm}$ & $\boldsymbol{\Delta}$ & $\mathrm{t}=25 \mathrm{~mm}$ \\
$\boldsymbol{v}$ & $\mathrm{t}=75 \mathrm{~mm}$ & $\diamond$ & $\mathrm{t}=19 \mathrm{~mm}$ \\
$\mathbf{x}$ & $\mathrm{t}=50 \mathrm{~mm}$ & + & $\mathrm{t}=12 \mathrm{~mm}$ \\
$\boldsymbol{\nabla}$ & $\mathrm{t}=38 \mathrm{~mm}$ & & \\
\hline
\end{tabular}

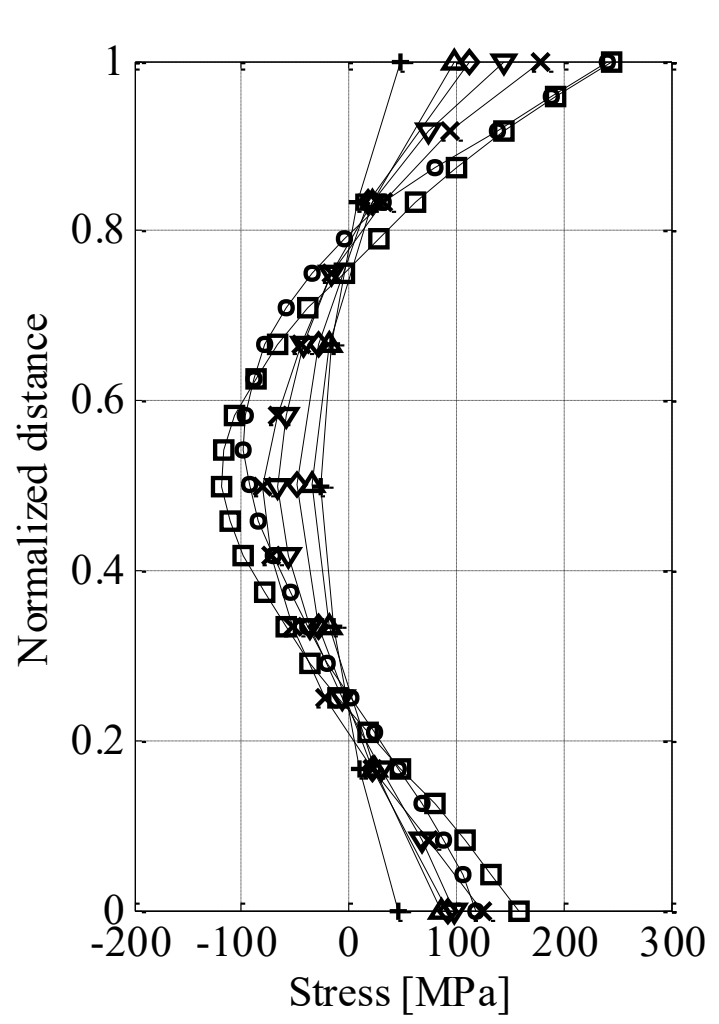

(b) Through-thickness residual transverse stress distribution at the HAZ

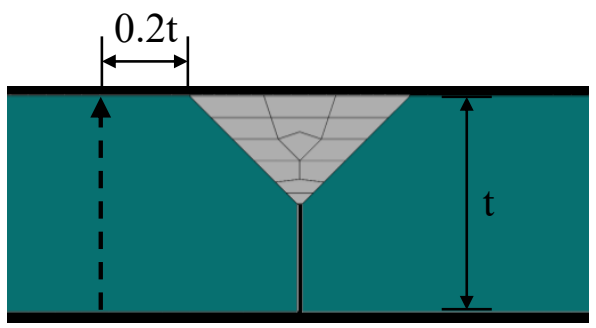

(a) Location of through-thickness measurement at HAZ

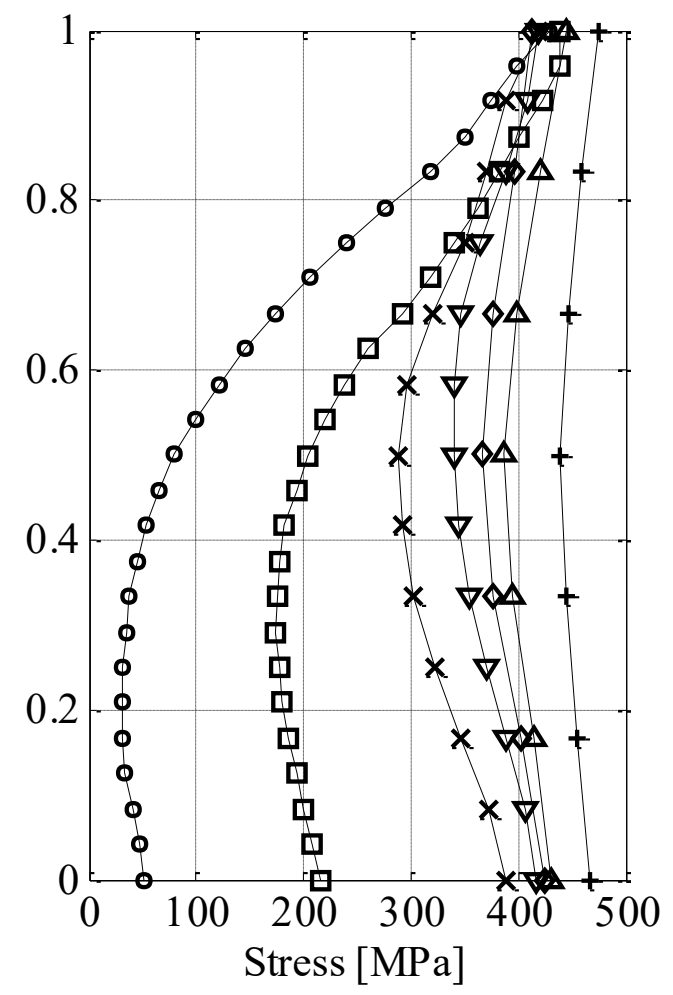

(c) Through-thickness residual longitudinal stress distribution at the HAZ

Figure 13: Transverse and longitudinal residual stresses through the plate thickness near the welding region for all plate thicknesses studied.

High variation in the longitudinal stresses through the thickness was also detected for thick plates (Figure 13c), while thinner plates exhibited a low variation in the longitudinal stresses but a higher average stress through the plate thickness. This is attributed to the more uniform through-thickness expansion and contraction in the welding direction for thin plates than thick plates; such that the whole thickness of the plate contributes to restraining the hotter regions from contraction. Figure 
14 shows the critical longitudinal crack sizes for all the studied thicknesses at a probability of crack initiation of 5\% according to the resulting stress levels at all the studied paths (Figures $3 \mathrm{~b}$ and $4 \mathrm{~b}$ ). The critical crack size increases with the decrease in thickness due to the lower transverse stresses (Figure 11), as well as the higher average fracture toughness based on CVN tests (Ibrahim et al., 2017).

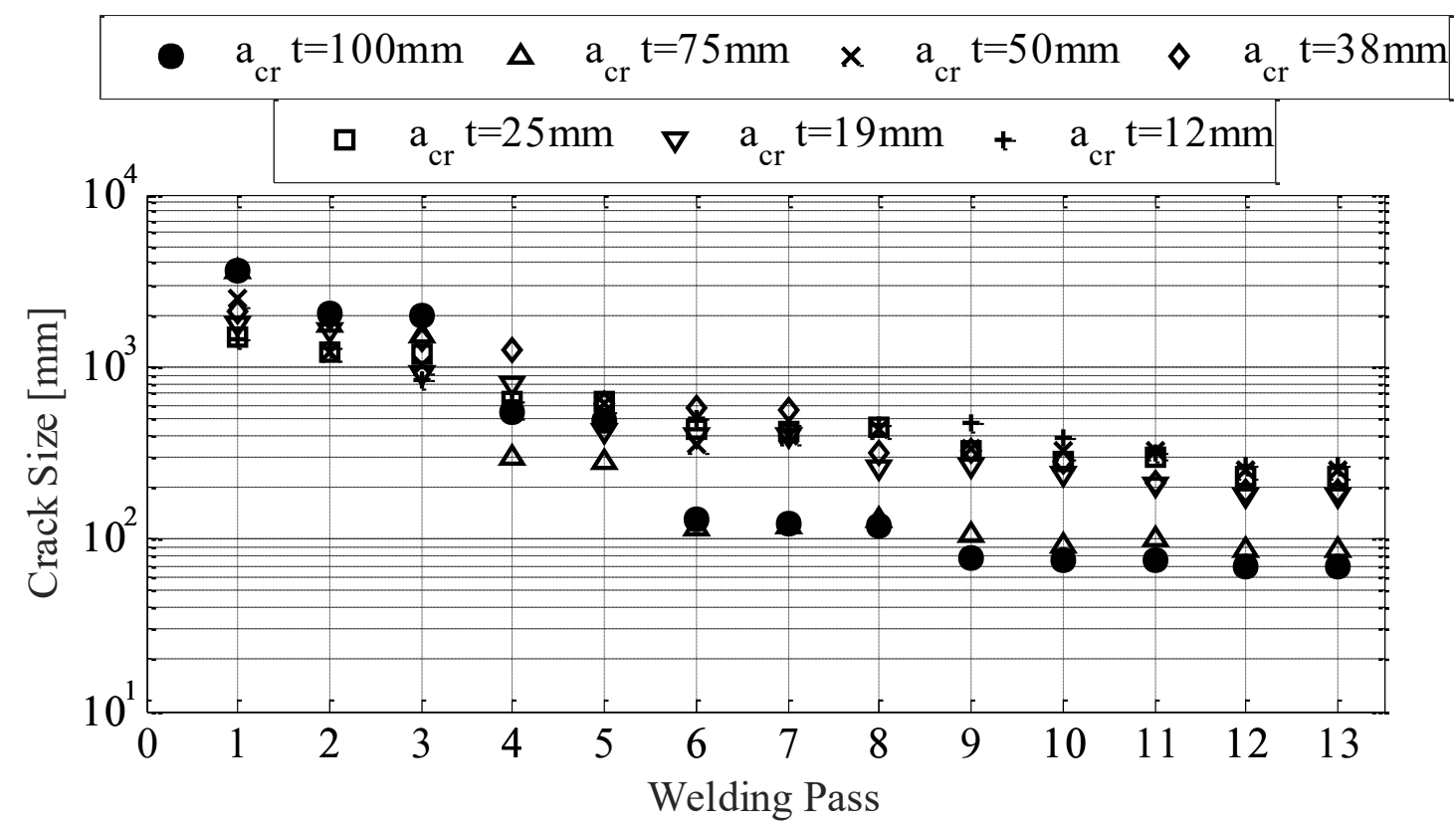

Figure 14: Effect of plate thickness on the critical crack size for a longitudinal crack at 5\% probability of initiation.

\subsubsection{Number of welding passes}

The size and number of the welding passes required for the welding procedure also have an impact on the resulting residual stresses. The reason is that this parameter controls the amplitude and number of heating and cooling cycles applied to the base metal. Figure 15a shows the four studied cases for welding a $75 \mathrm{~mm}$ thick plate; 5 welding passes (large size passes), 13 welding passes 
(commonly used number of passes according to feedback from the industry), 20 welding passes (small size passes) and the commonly used number of passes with unequal pass sizes.
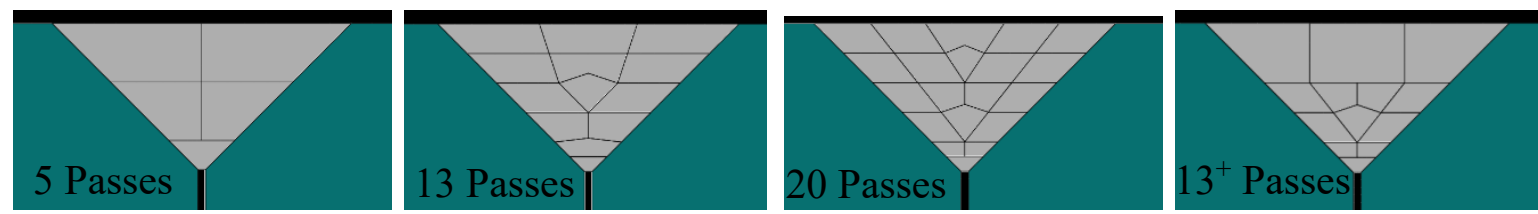

(a) Welding passes profiles for the four cases used in the study

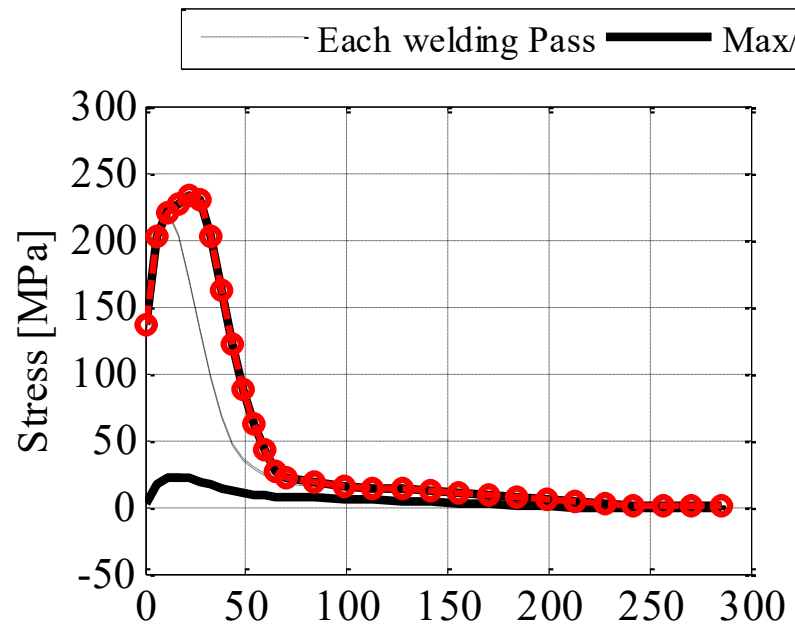

(b) Transverse stress distribution at Path-1a for 5 welding passes

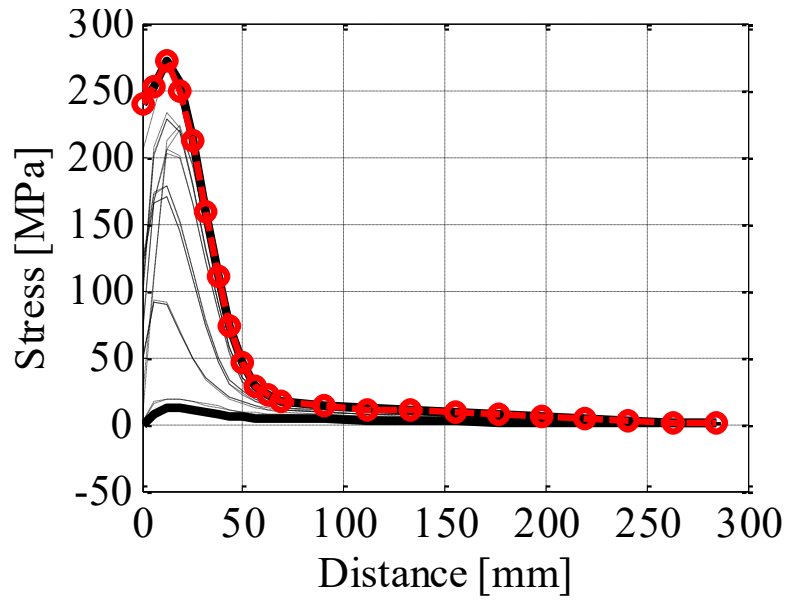

(d) Transverse stress distribution at Path-1a for 20 welding passes

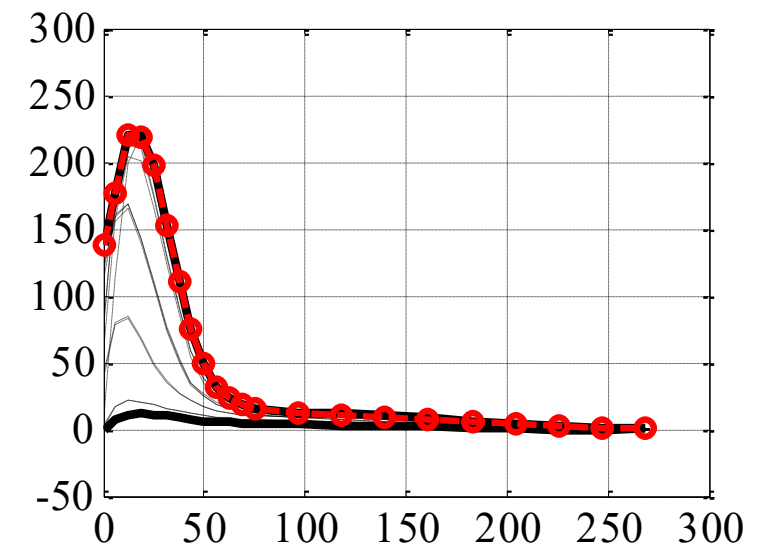

(c) Transverse stress distribution at Path-1a for 13 welding passes

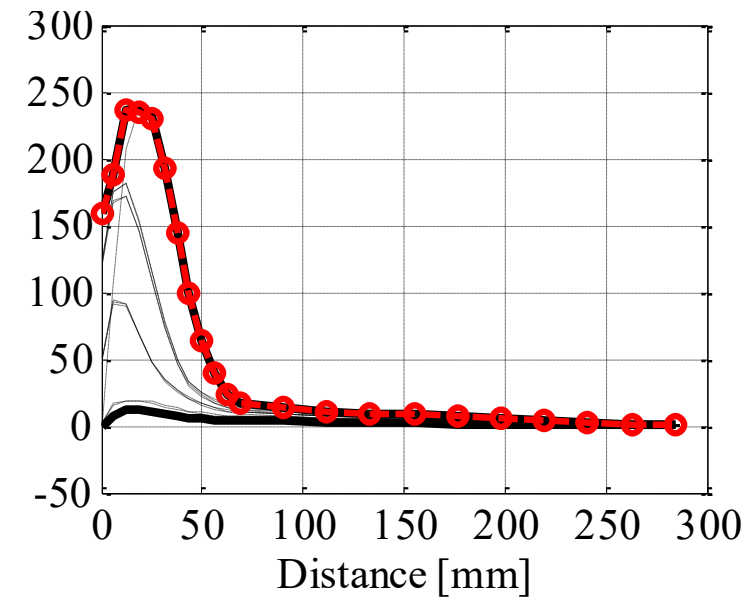

(e) Transverse stress distribution at Path-1a for modified 13 welding passes

Figure 15: Effect of number of welding passes on the transverse residual stress 
The weld assembly and overall size of the weld is the same for each case. The weld pass size can be made larger by increasing the number of electrodes, the heat input, the wire feeding speed or decreasing the welding travel speed or any combination of the above-mentioned parameters. The welding travel speed is considered constant for each of the studied cases (Tables 1 and 3). Figures $15 \mathrm{~b}$ to $15 \mathrm{e}$ show the transverse stress distribution along Path- $1 \mathrm{~b}$ of the flat plate model (Figure $3 \mathrm{~b}$ ) for the four studied cases. The graphs suggest that while the number of welding passes increases, the peak value of the transverse residual tensile stress near the welding area also increases. This is in agreement with experimental results reported by Bjorhovde et al. (1972) on 50mm thick plates. Furthermore, using a small number of welding passes results in a wider area of tensile stress near the welding region (Figure 15b) compared with the case where a larger number of welding passes are used (Figure 15d); thus a wider heat affected zone (HAZ). This is due to the higher heat input required to complete the large size welding passes. Also, there is no significant difference between the final residual stress distribution for the modified 13 welding pass procedure (Figure 15e) and the 5 welding pass procedure (Figure 15b). As such, it has been demonstrated that the size of the final welding passes has a greater impact on the residual stress distribution than the size of the welding passes at the early stages of the welding procedure, regardless of the number of passes. The through-thickness stress distribution for each of the studied welding procedures was also obtained. Figure 16a shows the location of the through-thickness studied path at the mid-span of the welded plates and at $15 \mathrm{~mm}$ from the edge of the welding. Figures $16 \mathrm{~b}$ and $16 \mathrm{c}$ show the transverse and longitudinal stress distributions, respectively. For the through-thickness transverse stresses there is no significant difference between the results of the different welding procedures. 

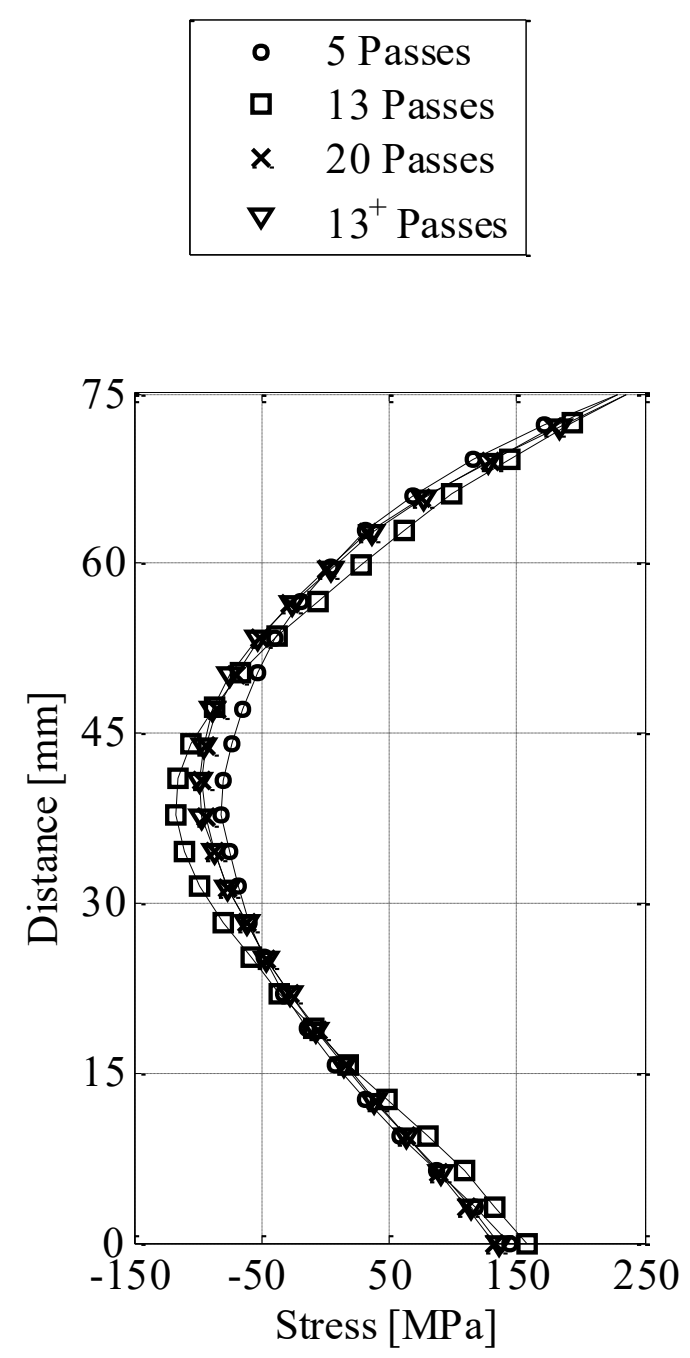

(b) Through-thickness residual transverse stress distribution at the HAZ

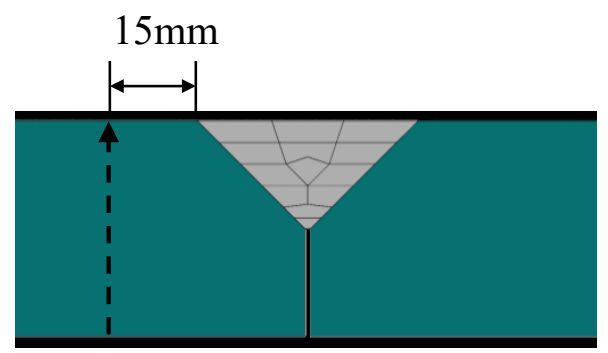

(a) Location of through-thickness measurement at HAZ

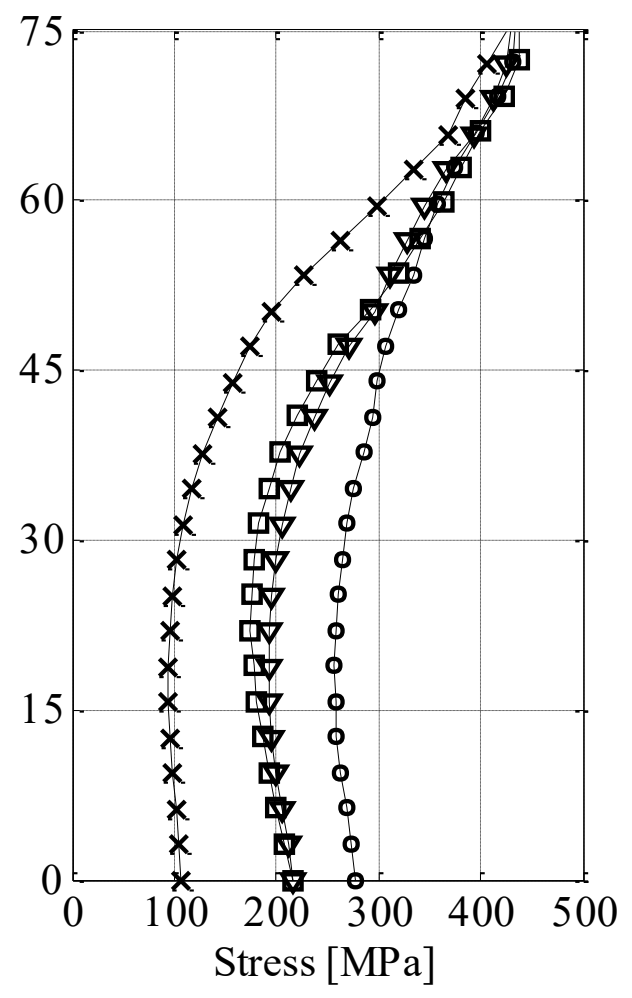

(c) Through-thickness residual longitudinal stress distribution at the HAZ

Figure 16: Transverse and longitudinal residual stresses through the plate thickness near the welding region for all cases of welding passes.

Using only 5 welding passes resulted in the highest through-thickness tensile longitudinal stresses, while using 20 welding passes resulted in the lowest tensile longitudinal stresses. The high heat input associated with using 5 welding passes results in more expansion strains than in the other welding cases. After cooling, higher tensile stresses are formed in the longitudinal direction than 
for the other welding cases constrained by the length of the welded plates. While in the transverse direction, the high heat input causes high expansion strains as well as a wide area of expansion. As a result, the constraint levels in this direction are low in comparison to the other welding cases; resulting in lower maximum residual stresses than the other welding cases. Moreover, Figure 17 shows a comparison between the developed plastic strains after completing half the weld for the 5 and 20 welding pass cases (the weld metal elements were removed from the figure to emphasize the strains of the base metal); the 5-pass case shows a wider plastic strain area than the 20-pass case.
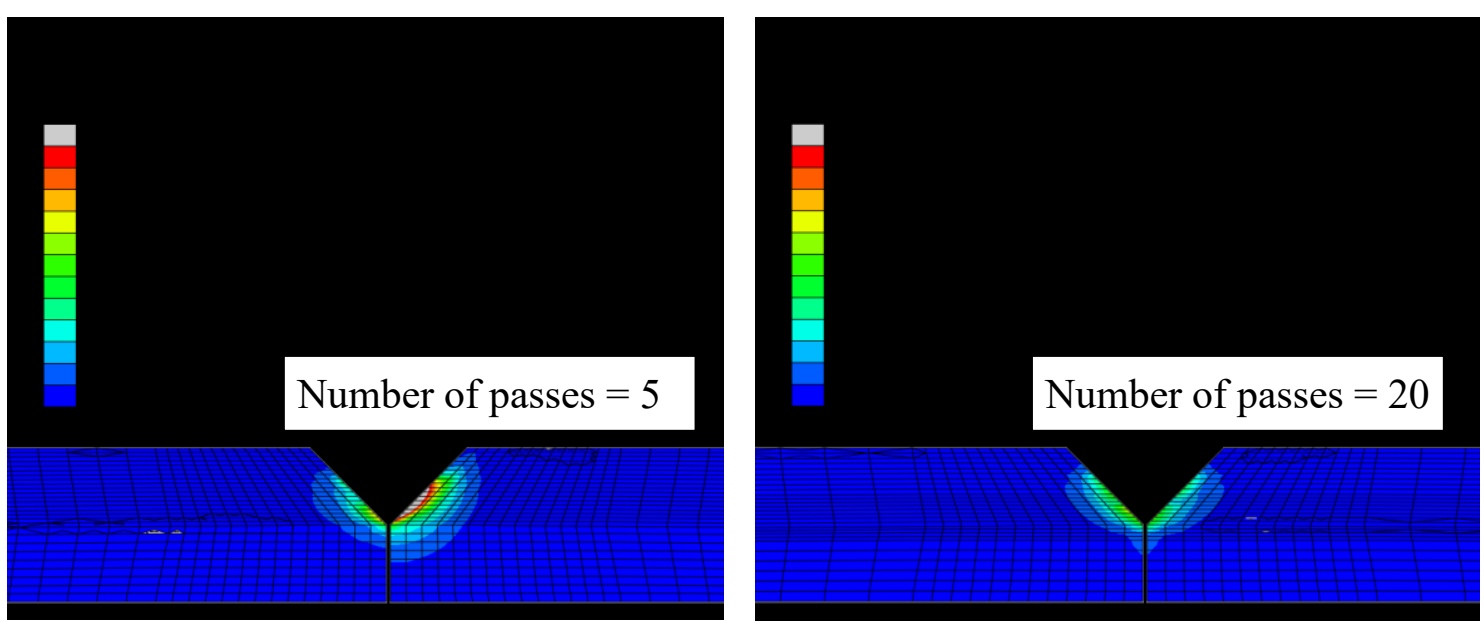

Figure 17: Transverse plastic strains after completion of half the welding procedure for the 5 and 20 welding passes cases.

Figure 18 shows the critical crack sizes in the longitudinal direction for a probability of crack initiation of $5 \%$ according to the resulting stress levels at all the studied paths (Figures $3 b$ and $4 b$ ). For the four studied cases, there is no significant difference in the critical crack sizes at the end of each welding procedure. Although the critical crack size for the 20 welding pass case is smaller than that of the 5 welding pass case due to the higher residual stresses, the 5 welding pass case has a wider HAZ, which increases the chance of imperfections being subjected to tensile stresses. 
Based on the stated results thick steel plates are sensitive to the number of heating and cooling cycles induced by the welding procedure.

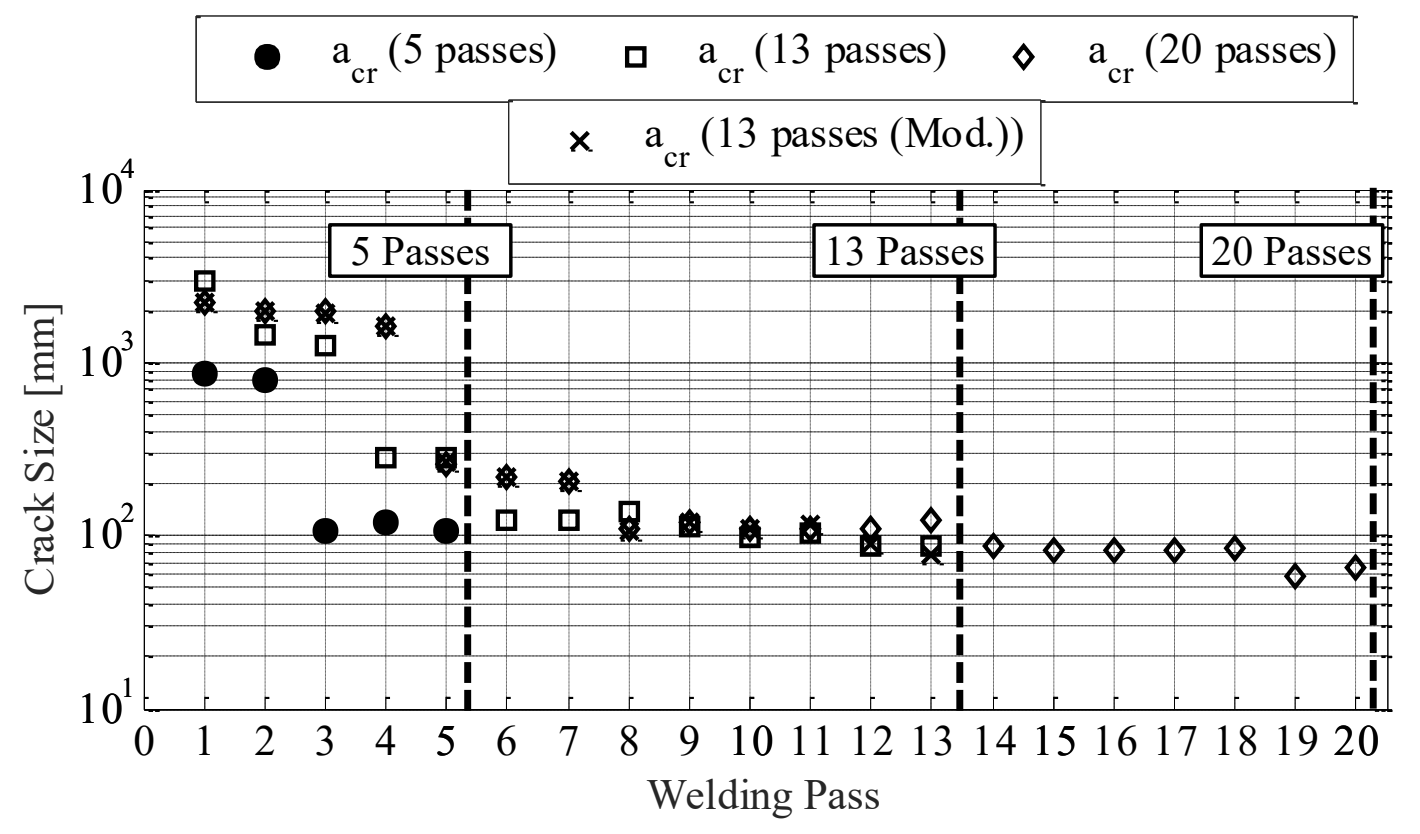

Figure 18: Effect of the number of welding passes on the critical crack size for a longitudinal crack at $5 \%$ probability of initiation

\subsection{Proposed Recommendations for welding thick steel plates}

Based on the results of the parametric study discussed in Sections 4.1 and 4.2 it can be concluded that the most critical parameters, that have the greatest impact on improving the resulting residual stress distribution and minimizing the probability of crack initiation in welded thick steel plates, are the preheat/inter-pass temperatures, the welding travel speed and the number of welding passes. The preheat and inter-pass temperature of $110^{\circ} \mathrm{C}$ that is mandated by the current welding specifications (AWS D1.1, 2010; CAN/CSA-W59, 2013) is essential and sufficient for the welding procedure of thick steel plates (thickness greater than 50mm). Moreover, using a slow welding travel speed of $5 \mathrm{~mm} / \mathrm{s}$ (high heat input) has the benefit of reducing the maximum tensile residual 
stress, however the HAZ size increases. If the resulting wide area in the base metal subjected to tensile stress leads to the initiation of discontinuities present in the base metal, the fabricator may instead select a faster welding travel speed of $15 \mathrm{~mm} / \mathrm{s}$ (low heat input) to provide a narrower tensile stressed area, however the maximum tensile stress is higher than that obtained with a fast welding travel speed. Another benefit of using a fast welding travel speed is increasing the production rate, which is an important factor in steel fabrication. The number of welding passes has the same effect as welding travel speed on the tensile stress values and distribution. Using a small number of welding passes (high heat input) results in a wide area under tensile stress with low maximum tension stress value, while using a large number of welding passes (low heat input) leads to a narrow area of tensile stress with high maximum tensile stress value. The application of fast and slow welding travel speed as well as small and large number of passes can be achieved by change the welding voltage, current and wire feeding speed accordingly.

Accordingly, four welding procedures are recommended for PJP groove welding of thick steel plates. All four procedures utilize a preheat/inter-pass temperature of $110^{\circ} \mathrm{C}$. The first welding procedure provides the lowest tensile stress value and widest tensile stressed area and is a combination of a welding travel speed of $5 \mathrm{~mm} / \mathrm{s}$ and 5 welding passes. The second welding procedure provides the narrowest area subjected to high tensile stresses and utilizes a welding travel speed of $15 \mathrm{~mm} / \mathrm{s}$ and 20 welding passes. The third welding procedure provides the highest fabrication rate using welding travel speed of $15 \mathrm{~mm} / \mathrm{s}$ and 5 welding passes. The fourth welding procedure provides the slowest production rate using a welding travel speed of $5 \mathrm{~mm} / \mathrm{s}$ and 20 welding passes, where, the other parameters such as the welding voltage, current and the wire feeding speed are adjusted accordingly. Figure 19 shows the residual stress distribution as well as the residual deformation (with a scale factor of 5) for the four recommended welding procedures 
assuming two $75 \mathrm{~mm}$ thick steel plates were welded in a flat position (the weld metal was removed from the figure to clarify the comparison between the welding procedures).

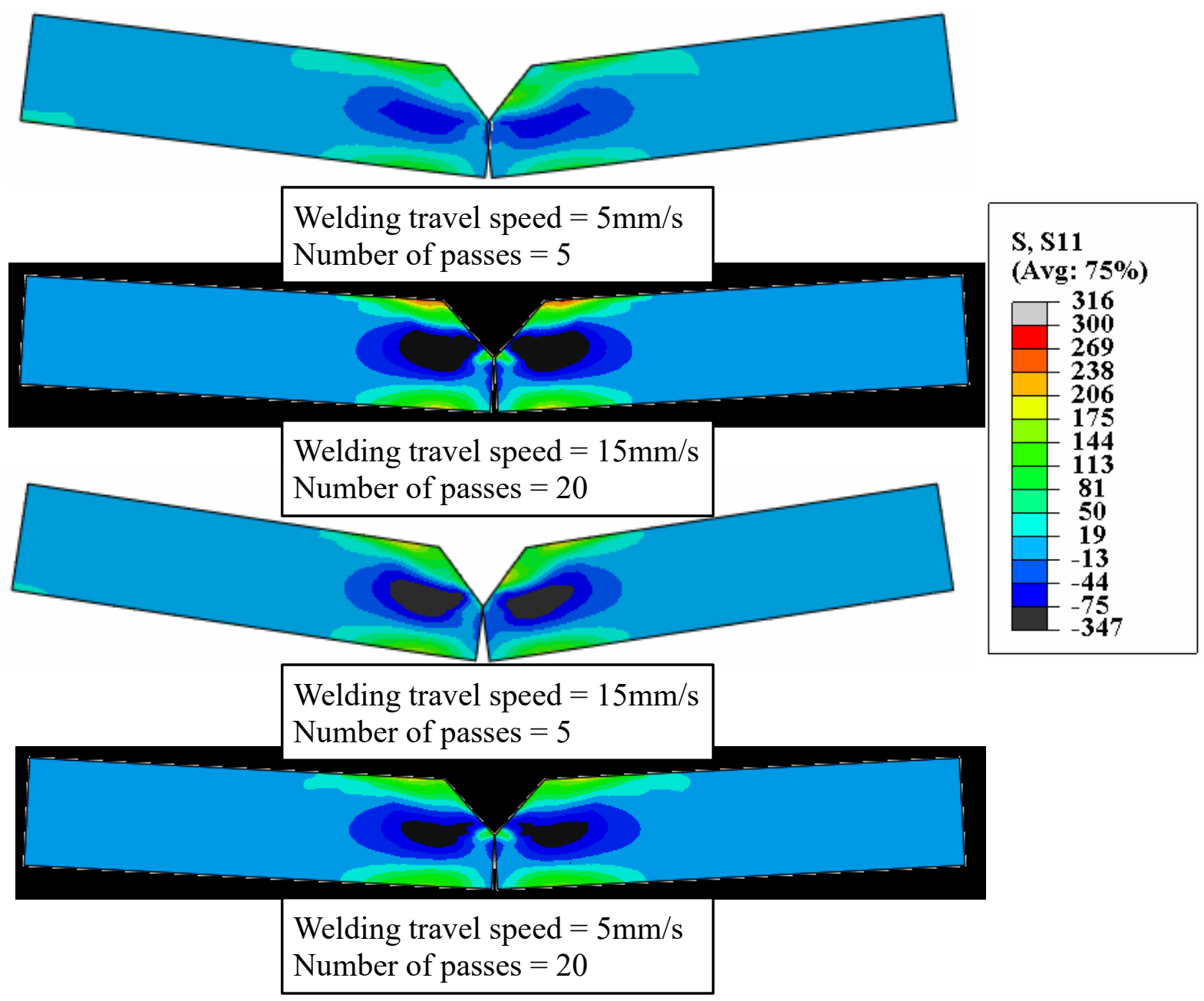

Figure 19: Residual transverse stress distribution and deformation $($ Scale factor $=5)$ for the four recommended welding procedures.

The results of the analyses of the four studied cases are in agreement with the parametric study results; such that the slow welding travel speed and small number of passes results in the lowest tensile residual stress distributed on the widest area, while the fastest welding travel speed and the largest number of passes resulted in the highest residual tensile stresses in the narrowest area. Furthermore, using a fast welding travel speed with a small number of passes resulted in the highest 
residual deformation due to high shrinkage strains, while using a slow welding travel speed with a large number of passes results in the smallest residual deformation (Figure 19).

A detailed analysis of the recommended welding procedures in combination with the crack assessment method based on fracture toughness tests developed by Ibrahim et al. (2017) was performed. In this analysis thick plates are divided into two categories according to the thickness ranges; 25 to $50 \mathrm{~mm}$ and 50 to $100 \mathrm{~mm}$. The analysis was developed for minimally and highly restrained welding conditions. Consequently, for welding thick steel plates, the base metal has to be inspected before welding for discontinuities and the following recommendation shall apply for the four welding procedures;

- The corresponding critical probability of crack initiation, with respect to the specifications' (AWS D1.1, 2010; CAN/CSA-W59, 2013) limit of 27J at $0^{\circ} \mathrm{C} \mathrm{CVN}$ value for ASTM A572 Gr.50 (2013) steel, is $2 \%$ according to Ibrahim et al. (2017).

- Provided in Table 5: the minimum distance from the edge of the plate to be welded, for surface and through-thickness discontinuities in the direction of the weld as well as in the transverse direction for each welding procedure. Such that the restraint to the deformation of the plates in the welding procedure is minimal for a probability of crack initiation of $2 \%$.

- Provided in Table 6: the minimum distance from the edge of the plate to be welded for surface and through-thickness discontinuities in the direction of the weld as well as in the transverse direction for each welding procedure. Such that the plates used in the welding procedure are fully restrained, for a probability of crack initiation of $2 \%$. 
Table 5: Recommendations for discontinuities in minimally restrained thick steel plates PJP butt-welded using an automated SAW procedure based on $2 \%$ probability of crack initiation.

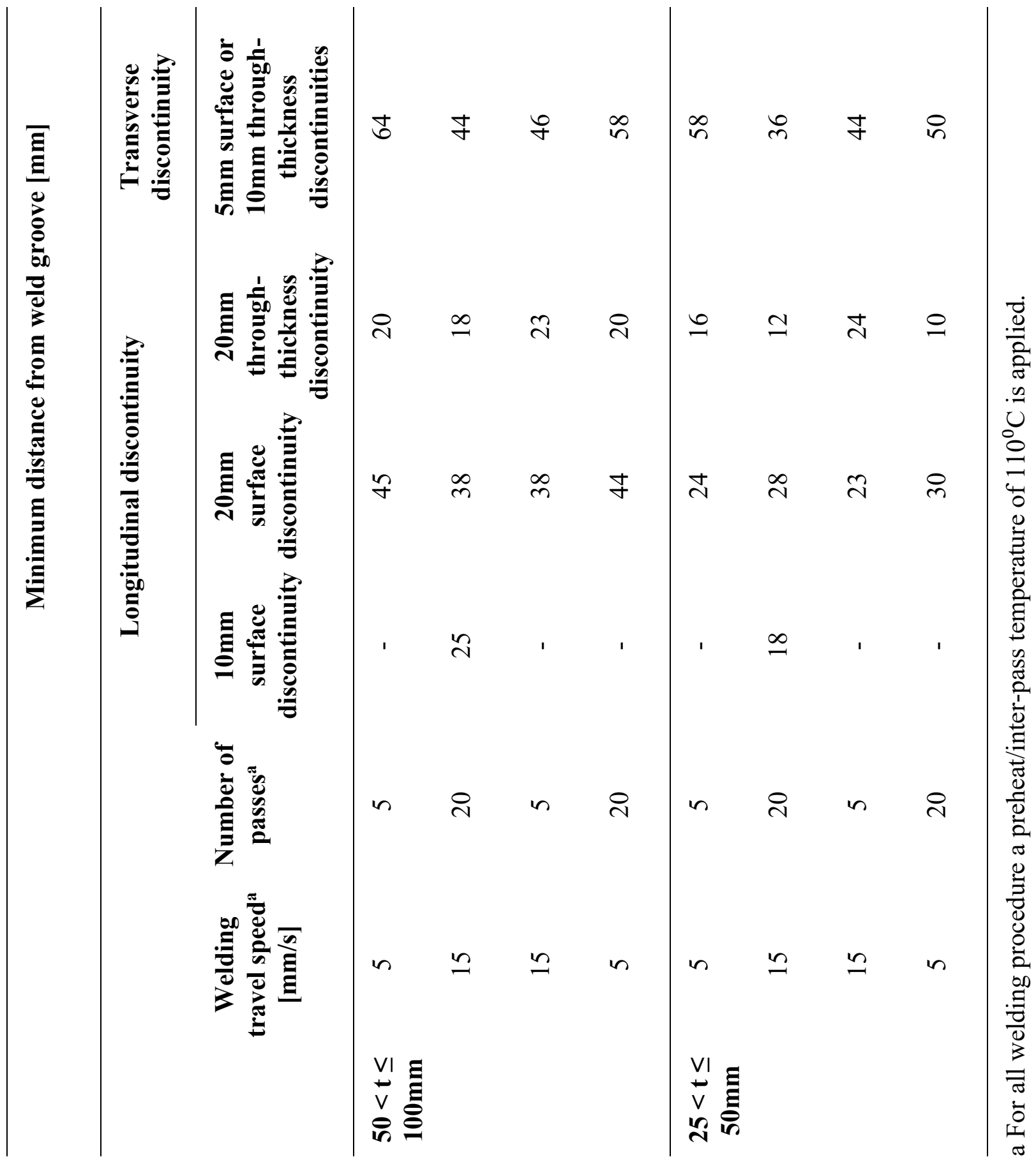


Table 6: Recommendations for discontinuities in fully restrained thick steel plates PJP buttwelded using an automated SAW procedure based on $2 \%$ probability of crack initiation.

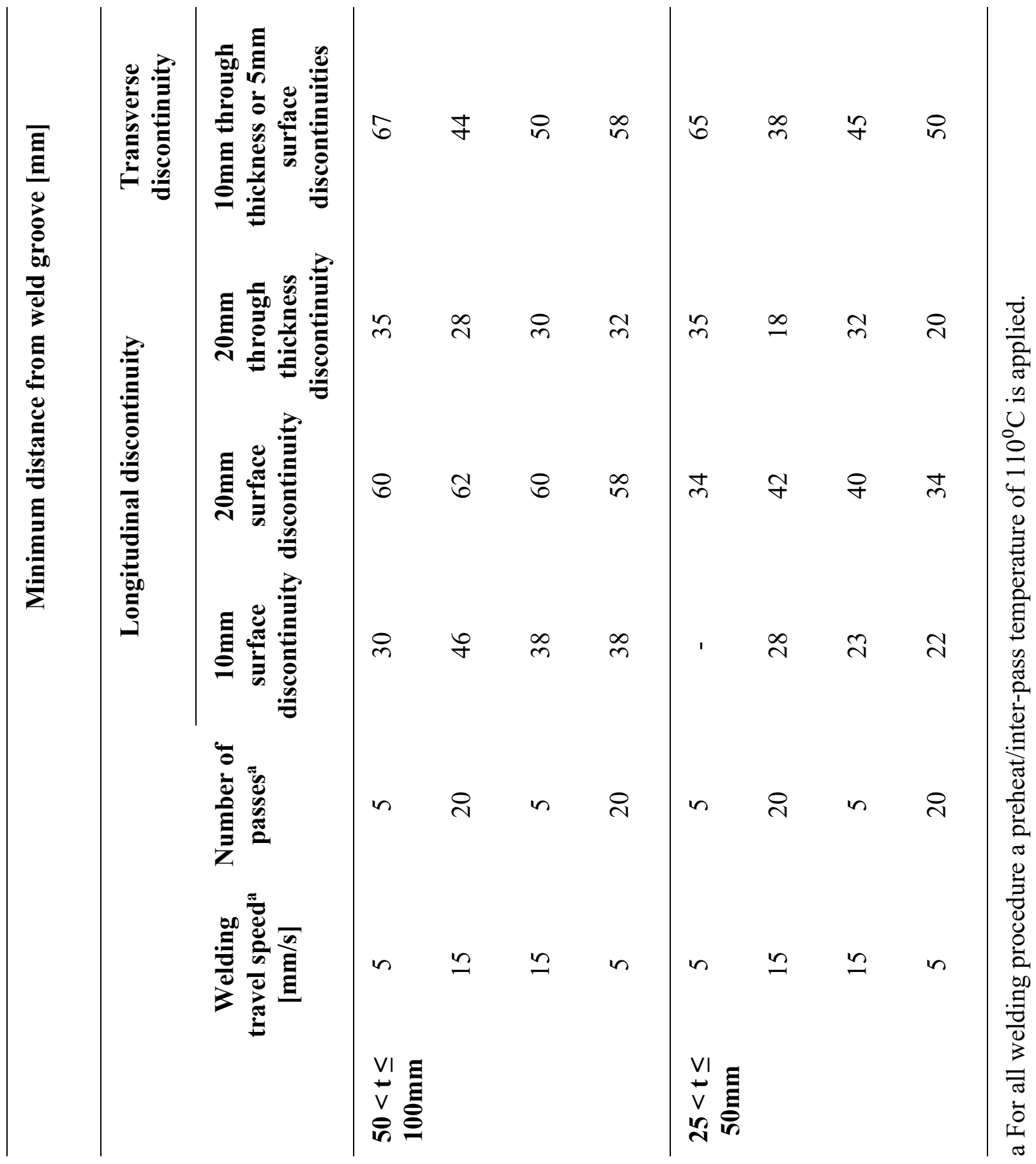


It is worth mentioning that the AWS D1.1 (2010) acceptability limits for laminar discontinuities in cut surfaces is $25 \mathrm{~mm}$. According to the results of this paper this limit should not be applied for thick steel plates undergoing a welding procedure; instead, Tables 5 and 6 should be employed. In addition, according to the residual stress results in the weld metal, the limitations of porosity and fusion discontinuities in the weld metal for welded steel plates with thickness greater than $50 \mathrm{~mm}$ should follow Clause 6.12.2.1 of AWS D1.1 (2010), which normally is for cyclically loaded nontubular connections in tension, because of the maximum discontinuity length of $12 \mathrm{~mm}$.

\section{Limitations of the Present Study}

The parametric study and recommendations for the welding procedures of welding thick steel plates were established for plates with thickness greater than $25 \mathrm{~mm}$ that are welded using the automated SAW process. This study is also limited to steel plates that are butt-welded using either complete joint penetration (CJP) or partial joint penetration (PJP). The crack assessment approach is based on fracture toughness data from ASTM A572 Gr.50 (2013) steel plates. The fracture toughness variability can be different for high strength steel grades as well as other steel materials (Kanno, 2016), therefore, further investigation is required for these cases.

\section{Summary and Conclusions}

In order to develop quantitative recommendations for the welding procedure of butt-welded thick steel plates using a SAW process, a parametric study was conducted for the welding procedure parameters. The study utilized a validated numerical simulation approach of the welding procedure for thick steel plates. The simulation was established for two welded assemblies; for a case study heavy built-up box column that are commonly used in high-rise steel frame building construction and two thick steel plates welded in a flat position. The parametric study was divided into two 
phases; the first phase focused on the heat input and cooling rate parameters of the welding procedure, the second phase focused on general parameters regarding the welding assembly. The study for each parameter was carried out such that the other parameters such as the welding voltage, current and the wire feeding speed were adjusted accordingly. The assessment of each parameter was based on its impact on the residual stress distribution and the critical crack sizes after each welding pass for a probability of crack initiation of $5 \%$. The main conclusions achieved from Phase A of the parametric study are summarized as follows:

- A low heat input that ensures full fusion of the weld and base metal is recommended. This is in agreement with the current code recommendations.

- Fast welding travel speeds result in a narrower high tensile stress area in the base metal than slow welding travel speeds; however, the maximum tensile stress values are higher.

- As the welding travel speed increase the area subjected maximum tensile residual stresses decrease.

- Applying preheat/inter-pass temperature is essential for welding thick steel plates; however, the improvement in the stress distribution achieved by applying temperatures greater than $110^{\circ} \mathrm{C}$ is not significant.

The main conclusions of Phase B of the parametric study are summarized as follows:

- The variation of material mechanical properties through the thickness of thick plates has a negligible effect on the welding residual stress distribution. An assumption of uniform material mechanical properties in the simulation is adequate within the range of applicability of the present study. 
- The welding tensile transverse residual stresses increase as the thickness of the welded plates increases. Longitudinal tensile residual stresses increase as the thickness of the welded plate decreases. Thin steel plates are more susceptible to deformation from the welding procedure than thicker plates.

- The variation in the through-thickness residual stresses increases as the thickness of the welded plate increases.

- Large number of welding passes results in a narrower tensile stressed area in the base metal and higher maximum tensile stresses than using a small number of welding passes.

- As the number of welding passes decreases the maximum transverse tensile residual stresses decreases.

- The number of welding passes has no significant effect on the transverse through-thickness residual stresses.

The welding travel speed, the preheat/inter-pass temperature and the number of welding passes were identified as the welding parameters with the highest impact on the developed residual stresses and the probability of crack initiation for the welding procedure of thick steel plates. Four welding procedures are recommended for butt-welding thick steel plates using an automated SAW process such that different combinations of fast and slow welding travel speed and a small and large number of welding passes were utilized. Numerical analysis of the four welding procedures was performed and acceptable limits for cracks and discontinuities in the base metal before welding were provided. 


\section{Acknowledgments}

The authors sincerely thank the ADF Group Inc. and DPHV Structural Consultants for their financial and technical support. The authors also acknowledge the financial support from the Natural Sciences and Engineering Research Council of Canada.

\section{References}

ANSI/AISC 360-10. (2010). "AISC 360-10, Specification for structural steel buildings." American Institute of Steel Construction, Chicago, IL, USA.,

ASTM A131. (2014). "A131/A131M-14, Standard Specification for Structural Steel for Ships, ASTM International, West Conshohocken, PA,

ASTM A516 Gr.70. (2015). "ASTM A516/516M-10(2015) Standard Specification for Pressure Vessel Plates, Carbon Steel, for Moderate- and Lower-Temperature Service,

ASTM A572 Gr.50. (2013). "A572/A572M-13a Standard Specification for High-Strength LowAlloy Columbium-Vanadium Structural Steel,

ASTM A709 Gr.50. (2015). "ASTM A709/A709M-15 Standard Specification for Structural Steel for Bridges,

AWS D1.1. (2010). "AWS D1.1 2010, Structural welding code-steel." American Welding Society, Miami, FL, USA.,

Bjorhovde, R., Brozzetti, J., Alpsten, G. A. and Tall, L. (1972). "Residual Stresses in Thick Welded Plates." Welding Journal, 51(8), S392,

Blodgett, O. W. and Miller, D. K. (1993). "The Challenge of Welding Jumbo Shapes." Welding Innovation, James F. Lincoln Arc Welding Foundation, X, 3-16,

CAN/CSA-W59 (2013). "CAN/CSA W59-13 Welded steel construction." Canadian Standards Association, Mississauga, Ont.

Chen, S. and Chang, S. C. (1993). "Residual Stresses in Welded Jumbo Box Columns." Journal of Constructional Steel Research, 25, pp. 201-209,

CWB/Gooderham-Centre (2005). "Welding for Design Engineers." Canadian Welding Bureau, 7250 West Credit Ave., Mississauga, ON, Canada L5N 5N1.

Fisher, J. W. and Pense, A. W. (1987, April 29-May 2). "Procedures for Thermal Cutting and Welding Heavy Structural Shapes." Proc. Proceedings of the National Engineering Conference and Conference of Operating Personnel, New Orleans.

Graville, B. A. (1975). "The principles of cold cracking control in welds." Dominion Bridge Co., Montreal.

Ibrahim, O. A., Lignos, D. G. and Rogers, C. A. (2013). "Estimation of residual stresses in thick steel plates due to welding through finite element simulation." Canadian Society of Civil Engineering, 3rd Specialty Conference on Material Engineering and Applied Mechanics, Montreal, Quebec,

Ibrahim, O. A., Lignos, D. G. and Rogers, C. A. (2016). "Proposed modeling approach of welding procedures for heavy steel plates." Engineering Structures, 127, 18-30, doi:http://dx.doi.org/10.1016/j.engstruct.2016.08.022 
Ibrahim, O. A., Lignos, D. G. and Rogers, C. A. (2017). "Probabilistic approach for assessing discontinuities in steel components based on Charpy-V-Notch tests." Engineering Structures, 147, 1-11, doi:https://doi.org/10.1016/j.engstruct.2017.05.016

Jefferson, T. B. and Woods, G. (1962). "Metals and how to weld them." (2d ed) James F. Lincoln Arc Welding Foundation, Cleveland,.

Kanno, R. (2016). "Advances in Steel Materials for Innovative and Elegant Steel Structures in Japan-A Review." Structural Engineering International, 26(3), 242-253,

Miller, D. K. (2006). "AISC Steel Design Guide 21 Welded Connections - A Primer for Engineers." American Institute of Steel Construction, Chicago, IL.

Miller, D. K. (2010). "Welding heavy Structural Steel -- Successfully." 2010 NASCC: The Steel Conference, Orlando, FL, USA,

Pilipenko, A. (2001). Computer simulation of residual stress and distortion of thick plates in multielectrode submerged arc welding. Their mitigation techniques. (Ph.D. dissertation), Norwegian University of Science and Technology, N-7491 Trondheim, Norway.

Society of Fire Protection Engineers (2008). "SFPE handbook of fire protection engineering." (4th ed) National Fire Protection Association, Quincy, Mass. Bethesda, Md.

Yang, Y. (2008). The effect of submerged arc welding parameters on the properties of pressure vessel and wind turbine tower steels. (Master of Science), University of Saskatchewan, Saskatoon. 